\title{
THE EPIGENOMIC ANALYSIS OF HUMAN OBESITY
}

Christopher G. Bell1-4

'MRC Lifecourse Epidemiology Unit, University of Southampton, Southampton, United Kingdom

2Epigenomic Medicine, Biological Sciences, Faculty of Environmental and Natural Sciences, University of Southampton, Southampton, United Kingdom

3Human Development and Health Academic Unit, Institute of Developmental

Sciences, University of Southampton, Southampton, United Kingdom

${ }^{4}$ Department of Twin Research and Genetic Epidemiology, King's College London,

London, United Kingdom

${ }^{*}$ Corresponding Author: $\underline{c g b @ m r c . s o t o n . a c . u k}$ 


\section{ABSTRACT}

The epigenome - the chemical modifications and packaging of the genome that can influence or indicate its activity - gives a molecular insight to cell-type specific activity. It can, therefore, reveal the pathophysiological mechanisms at work in disease. Detected changes can also represent physiological responses to adverse environmental exposures, thus enabling the epigenetic mark of DNA methylation to act as an epidemiological biomarker, even in surrogate tissue.

This makes epigenomic analysis an attractive prospect to further understand the pathobiology and epidemiological aspects of obesity. Furthermore, integrating epigenomic data with known obesity-associated common genetic variation can aid in deciphering their molecular mechanisms.

This review primarily examines epidemiological or population-based studies of epigenetic modifications in relation to adiposity-traits, as opposed to animal or cell models. It discusses recent work exploring the epigenome with respect to human obesity, which to date have predominately been array-based studies of DNA methylation in peripheral blood. It is of note that highly replicated BMI DNA methylation associations are not causal, but strongly driven by co-associations for more precisely measured intertwined outcomes and factors, such as hyperlipidaemia, hyperglycaemia and inflammation. Finally, the potential for the future exploration of the epigenome in obesity and related disorders will be considered. 


\section{INTRODUCTION}

Epigenetic factors include the chemical modifications of DNA and the proteins that the DNA wraps around, which influence or may indicate the activity of genes. Deciphering these marks can be a powerful method to understand the specialised functioning of a cell and organs (1). Furthermore, they may inform how molecular mechanisms are impeded in disease or due to adverse environments.

Obesity rates have increased at such a magnitude that this clearly points towards non-genetic, or environmental factors, as the significant driver. Identified genetic susceptibilities are also modulated by these external influences $(2,3)$. This has led to considerable interest in the study of the epigenome with the potential to quantify gene activity changes due to this environment, as well as the possibility of gaining molecular understanding of the pathophysiological consequences of the obese state. Crucial biological understanding of obesity and its consequences are still lacking $(4,5)$ and would help focus vital preventative measures to counter obesity's substantial morbidity and mortality risk (6).

\section{THE EPIGENOME}

DNA is packaged at the strand level by wrapping around Histone proteins that comprise of 8 subunits, two of each of Histone 2A, 2B, 3 and 4. The histone proteins possess tails that can be post-translationally modified, including the addition of methyl or acetyl groups to Lysine $(K)$ molecules on histone $3(\mathrm{H} 3)$. These additions can be related to active or repressed regions depending upon which $\mathrm{K}$ is modified. Amino acid deviation in the protein structure of these histone molecules, termed Histone Variants, also modify activity and can as well be associated with disease processes (7).

Chemical modifications of DNA itself include the most common, stable and well-studied, DNA methylation, or the addition of a methyl group onto the 5' carbon of cytosine. This robust chemical mark is due to the strong covalent carbon-to-carbon bond that connects cytosine to the methyl group. In differentiated cells this occurs in the DNA sequence predominately 
within the context of a CPG dinucleotide, that is where Guanine follows Cytosine in the 5' to 3' direction on one DNA strand. It acts canonically as a repressive mechanism within gene promoters. However, additional DNA modifications occur, and these are in fact progressive oxidative products of the active DNA demethylation process, driven by the TET enzymes, leading firstly to hydroxymethylcytosine $(5 \mathrm{hmC})$, formylcytosine $(5 f C)$ and then carboxycytosine $(5 \mathrm{caC})$. This final product is then recognised by the baseexcision pathway to enable return to an unmodified cytosine (8). These less common modifications may also in themselves possess active roles, with $5 \mathrm{hmC}$ implicated functionally within enhancers (9).

High-throughput analysis of the epigenome is focused now on DNA methylation, particularly because of its stability in extracted DNA in comparison to other epigenetic marks, such as histone modifications. However, due to its biological plasticity it is an attractive biomarker with strong potential clinical utility (10).

\section{CONSIDERATIONS IN THE ANALYSIS OF THE EPIGENOME}

To powerfully examine the epigenome, especially in a human population setting (11), it is necessary to be clear how this mechanism contrasts from the genome. This understanding impacts significantly on design, analysis and interpretation. The differences can be broadly encapsulated in three principles: i) cell-type specificity ii) changeability and iii) sequence interactive (or positional) effects.

Firstly, as its function dictates, the epigenome is tissue or cell-type specific. Therefore, we wish, if at all possible, to be examining the cell-type(s) that are most relevant to the pathophysiology of the disease. We can only interpret any associated findings in tissue that is not the primary site of action as a surrogate measure for markers of exposure, which may also act on the organ of disease, or downstream physiological changes due to these exposures or disease outcomes. In the analysis of obesity this is not straightforward, as the intrinsic genetic predisposition is governed largely within the brain (12), with central control for energy balance directed by specific hypothalamic neurons, particularly within the arcuate nucleus (13). 
Thus, these cells are inaccessible except in post-mortem samples. Adipose tissue is also an obvious focal interest for the dissection of obesity, with the physical and functional changes that occur to it and its role as an endocrine organ (5).

Secondly, the epigenome is changeable over time. This is most dramatic during development, where two rounds of epigenomic reprogramming occur, firstly in gamete formation and then secondly postfertilisation. These are both characterised by global DNA demethylation (14). However, the epigenome is not static from this time-point. It is seen to suffer from 'epigenetic drift' with age, whereby hypomethylated regions gain and hypermethylated regions lose methylation over time stochastically throughout the genome (15). This process is proposed to be involved in age-related deterioration in function, and the concurrent increased risk of chronic diseases, such as obesity-related conditions. Though, on top of this are specific directional ageing changes that can be identified at defined functional loci across the genome $(16,17)$.

Thirdly, positional effects driven through sequence variation will be reflected in the measured epigenome. These can be direct, in cis, or trans, and can bedevil the analysis in human population samples, particularly across diverse ancestries (11) (Figure 1). Direct effects with respect to DNA methylation can be due to genetic polymorphism at the CPG dinucleotide itself. In fact, almost $\sim 1 / 3$ of SNPs occur at CpG locations, because of the hypermutability of methylated cytosines, and this contributes considerably to allelic variation in the DNA methylome $(18,19)$.

The observed epigenetic state may represent the activity or repression of local cis-regulatory elements (CREs) (Usually 100-1000 bp in length) (20). Genetic variability within these regions can led to fixed obligatory epigenetic positions or facilitate epigenetic variation (21). Genetic effects on the methylome via transcription factors (TFs) has been known for decades, such as the role of SP1 within CPG islands (22). Motif changes in this and other Methylation Determining Regions (MDR), such as those for CTCF and RFX, give rise directly to methylation variation in CPG dense regions (23). TFs binding to transcription factor binding sites (TFBS) can also drive down DNA methylation (24) at distal regulatory regions and thus genetic variation in these binding 
sites will also be influential. Some TFs are explicitly sensitive to DNA methylation (25) and some, in fact, require it in order to bind (26). Also SNPs affecting the expression of trans factors will impact on the epigenetic state within their distal TFBS or CRE regions (27). Genetic influence on the epigenome is in fact so strong that it can be observed in enhancer variation in only 19 individuals of diverse ancestry (28).

Nearby positional effects such as polymorphic insertions of often heavily methylated retrotransposons will influence the local region (29). The density of CpGs also has a direct relationship with the DNA methylome (30), so CPG-SNPs (SNPs creating or abrogating a CpG dinucleotide $(18,31)$ ) as well as affecting available methyl-C containing motifs, can impact on the rate of change of $\mathrm{CPG}$ density slopes. The influence of SNPS as MQTL (methylation QTL) (32), can capture impact upon cis or trans factors, the DNA methylation machinery, or haplotypic effects, such as regional density or proximity factors. Genetically-associated correlated CpGs can be observed to cluster, which have been termed 'GeMes' (33). Finally, the epigenome is a coordinated mechanism so the epigenetic layers should fit logically together, such that a DNA hypermethylated promoter should show lack of co-locating activating chromatin marks and vice versa (34).

\section{CONFOUNDING ISSUES}

All the above effects, tissue-specificity, changeability, and sequence interaction, can therefore confound or misattribute action or effect in epigenomic studies. To mitigate against these, rigorous study designs have been proposed and employed. However, due to practical, technical and cost considerations, it is often not possible perform the ideal study, but to compromise, acknowledge and work within these limitations $(35,36)$.

Isolating disease-relevant tissue cell-types for analysis is an obvious first starting point. However, many large epidemiological studies have DNA derived from peripheral blood available, with the positive that these are often sizeable numbers and possess deep phenotyping. Whilst these are the practicalities, an argument may be made that peripheral blood is of interest physiologically in obesity due to known inflammatory related changes (37) or 
for detection of passive exposure biomarkers. Furthermore, the potential clinical utility of findings in blood is significant due to its comparative ease of access compared to fat-tissue biopsy. However, these DNA methylation differences will be unlikely to correlate with other target tissues. Postmortem samples or tissue biopsies are required to gain further insights into underlying mechanisms.

The additional factor regarding peripheral blood analysis is that it comprises of the various leukocyte cell-types and as such represents a metaepigenome of these subsets contained (38). This mixture needs to be quantified and even in normal conditions these vary between individuals due to many factors including sex and genetic background. Thus, DNA methylation profiling in blood will strongly identify signals driven by sub-cell composition changes due to the disease state or immune responses associated with it. Whilst isolation of the most disease relevant cell-type is preferable (39), deconvolution algorithms have been devised using Differentially Methylated Positions (DMPs) that estimate leukocyte cell-type proportions (40). In fact, due to the cell-type specificity of epigenomes, once accurately delineated, this deconvolution is set to become one of the most powerful epigenomic tools. The mapping of these cell and tissue types is beginning through efforts such as the Epigenomics Roadmap (41), Blueprint (42) and future cell-type defining surveys (43). Kim et al. have recently shown that an expanded set of reference leukocytes, with pathologically important cell fractions comprising immature, memory plasma B cells, activated Natural killer cells and naïve $T$ cells, can explain significantly more variability in peripheral blood methylomes (44). Additionally, these data improved case and control discrimination in immune-related disorders, including the metabolic syndrome.

Changeability in developed tissues encapsulates two oftenintersecting mechanisms. Firstly, significant directional changes with time in proportions of a heterogeneous collection of cells, and secondly, the activation or representation of certain pathways. Relative change is seen clearly, as mentioned, in peripheral blood, with responses to acute infection or even chronic low-grade inflammation (45). Other significant proportional changes occur due to ageing, with a skew towards a greater myeloid cell 
fraction in blood (46), but also a reduced ratio of neurons to glia in the brain (47). However, in many studies the phenotype of interest may alter the proportional composition of the cell types within the analysed target tissue (48). In fact, in some cases, correction for cell-type may impede the identification of cell-type specific modifications (49).

Finally, the influence of genetic factors on the epigenome is strong. Therefore considerable power comes from longitudinal studies (35), or monozygotic (MZ) or identical twin discordant analyses, to remove these significant influences $(50,51)$. In high-throughput DNA methylation array analysis the influence of genetic effects can be driven by SNPs at the investigated CpGs themselves, under the probes, or nearby (Figure 1). Drastic effects led to discrete genotypic grouping or "gap signals", with 11,007 seen in a recent Illumina Infinium Human Methylation450 bead chip (450k array) analysis (52). Previous 450k array analysis has found population genetic variation attributable in 66,877 probes (13.8\%) (53). Chen et al. observed recently this strong genetic influence in a study of genetic drivers of epigenetic variation in human immune cells and it was noted to be a concern for EWAS interpretation (54). More complex haplotyptic effects may also exist, with strong consequences captured by "gap signals", though more subtle outcomes will converge. Although how these genetic influences cannot only confound studies, but also may facilitate functional variation, should also be borne in mind. CpG-SNPs are proposed to play a significant facilitative epigenetic role and these effects were recently seen be to enriched within GWAS regions in a number of studies, including Type 2 Diabetes (55-57)

\section{CELL-TYPE SPECIFIC SIGNALS IN PERIPHERAL BLOOD}

Dissecting the strong DNA methylation signals that can be identified with tobacco smoking in peripheral blood starts to reveal the biological intricacies of epigenetic changes in this heterogeneous tissue. Understanding these robust results is very useful in interpreting what may be possible in DNA methylation studies of obesity and other diseases. There are distinct results dependent upon which cellular subset is examined (58). The strongest 
tobacco-associated signal in the gene AHRR appears so conspicuously as the epigenetic change occurs specifically within granulocytes and monocytes and is then amplified by the fact that smoking itself increases the proportion of granulocytes in peripheral blood. By contrast tobacco has little impact on AHRR T cell DNA methylation. In comparison, lymphoid-specific inflammatory changes, such as those seen in GPR 15, where DNA methylation changes are only seen in T and B cells $(58,59)$. Biologically these changes are likely inflammatory responses driven by smoking injured tissues. On the myeloid side, monocyte to macrophage differentiation is influenced, as well as a proposed carbon monoxide environmental selection on bone marrow progenitor cells (58). Thus, the identification of these subtype specific signals enable novel hypotheses and mechanism to be proposed and explored.

\section{OBESITY-INDUCED CHANGES IN FAT AND BLOOD}

Fat tissue is not a homogenous organ. The adipocytes of subcutaneous fat are mostly white adipocytes, due to triglyceride storage, which are leptin and adipokine-secreting. Additionally, there are small but discernable levels of brown and beige fat (5). The role of brown fat in humans has gained significant interest due to its energy-dissipation properties and fat burning actions via uncoupling protein 1-containing mitochondria. Stimulation by the sympathetic nervous system after cold exposure leads to heat production. Beige, or brown-to-white thermogenic adipocytes, have a progenitor cell origin and conversion can be induced by cold temperatures, exercise and endocrine factors (5).

In obesity, adipose tissue becomes a large immunologically active endocrine organ (60). Infiltration by macrophages and other inflammatory immune cells occurs, partly due to obesity-related apoptosis of adipose cells (60). This leads to chronic adipose tissue inflammation (61) with the secreted proinflammatory cytokines contributing to the insulin resistant state that arises (62). Visceral fat deposits, including the omentum and mesenteric fat, are more detrimental than subcutaneous (63) and are associated with many of the systematic metabolic consequences of obesity (5). 
Obesity induces changes in innate immune cells, but also increases in $\mathrm{CD} 4^{+}$and $\mathrm{CD}^{+} \mathrm{T}$ cells and reduces tolerance-promoting regulatory $\mathrm{B}$ cells as well as inducing abnormal B cell function (64). There is a proposed role in obesity of lymphoblast-derived Natural Killer (NK) cells, which are shown to be significant regulators of macrophage polarization and insulin resistance (65), and their methylome is remodelled in conversion from naive to activated cells (66). Chronic low-grade inflammation is associated with obesity, and specific DNA methylation changes are observed, due to this state, assessed via Creactive protein levels (CRP), within peripheral blood (45).

\section{ANALYSIS OF THE EPIGENOME IN OBESITY}

Studies of obesity epigenetics up to the beginning of this decade were predominately either targeted candidate genes or total measures of the epigenome, such as global DNA methylation (67). The later can be useful in gross abnormalities, such as cancer, when significant hypomethylation is strong enough to drive global variation. Though it is far less useful in more nuanced phenotypes and has not lead to consistent findings (68). With the former, as was the experience in complex trait genetics, the study of candidate genes has not been particularly fruitful, with weak and again inconsistent effects. In the exploration of imprinting genes or those involved in metabolism, few (if any) have been supported by subsequent genome-wide, more powered and confounding-aware studies (68). Many early studies therefore need reassessing in the light of current findings and knowledge.

All DNA methylation studies prior to at least 2012 are likely to have not taken the confounding effects of cell-type proportions into account. Furthermore, many of these studies are in small numbers, with added potential issues due to genetic heterogeneity. Whilst stronger effect size epigenetic associations can be found for phenotypic traits or complex diseases than genetic associations (69), lack of subsequent replication point to their weakness (68). 


\section{EPIGENOME-WIDE ASSOCIATION STUDIES FOR OBESITY (BMI) IN}

\section{PERIPHERAL BLOOD}

In 2014 Dick et al. published one of the first large Epigenome-wide Association Study (EWAS) for BMI using the 450k array (70). This was performed in whole blood derived DNA in European ancestry individuals. The initial discovery set was 479 individuals, followed by two rounds of replication, firstly in 339 and then secondly in 1,789 samples. The discovery set identified 5 CpGs across 3 genetic loci associated with BMI. Three CpGs replicated and these all resided in the first intron of HIF3A, the Hypoxia Inducible Factor 3 Alpha Subunit gene, involved in regulating hypoxia-inducible gene expression (cg22891070, cg27146050, and cg 16672562). Potential lymphocyte cell-type effects on cg22891070 were tested for, after the initial analysis. Whilst a small association with leukocyte number was seen, adjustment for subtypes did not substantially reduce the BMI association.

Then to investigate HIF3A across different tissues, DNA from adipose tissue $(n=635)$ and skin ( $n=395)$, was assessed, with significant methylation changes identified in adipose only. One driver of this may be the high level of inflammatory blood cell invasion into adipose tissue. Genetic effects were explored and 2 SNPs (rs8102595 \& rs3826795) were both independently associated with cg22891070's DNA methylation state in all datasets, although were not themselves significantly associated with BMI.

As well as being replicated in a number of studies (71-73), including in adipose tissue (74), this result was also explored for causality in the ALSPAC cohort from Bristol, U.K. (75). Genetic and multiple time point DNA methylation data was available in $\square 1,000$ mother-offspring pairs. The DNA methylation changes were proposed to be secondary to differences in BMI, through examination of the temporal relationship of changes in sequential data, not causal, which was also supported by Mendelian Randomisation (MR) analysis. In further analysis by Main et al. a relatively high level of familiarity ( $h^{2} 51-64 \%$ ) for HIF3A DNA methylation in blood was observed (76), in fact a similar level to obesity itself. Epidemiological evidence has also pointed at vitamin B2 and B12 levels influencing HIF3A epigenetic levels (73). 
Another BMI EWAS analysis with the 450k array in peripheral blood DNA was performed in 2,097 African American adults in the Atherosclerosis Risk in Communities (ARIC) study (72). A similarly sized replication set of 2,377 European ancestry derived individuals from the Framingham Heart Study was employed, as well as isolated CD4+ T cell DNA from 991 European ancestry individuals (Genetics of Lipid Lowering Drugs and Diet Network Study). This enabled 37 DMPs to be robustly identified with BMI and an additional DMP specifically associated with Waist Circumference only. 16 DMPs were also seen to be consistent in 648 adipose tissue samples. Novel results included LGALS3BP, KDM2B, PBX 1 and BBS2, and genes implicated in lipid metabolism, cytokine signalling and immune response.

In a recent study Wahl et al. analysed a collection of large GWAS cohorts with the 450k array in peripheral blood (77). The discovery cohort contained a mix of South East Asian $(n=2,680)$ and European $(n=2,707)$ ancestry individuals and identified 278 BMI-associated CpGs residing in 207 genetic loci whilst correcting for leukocyte cell-type proportions. Taking forward the strongest individual CpG associations within these regions to an additional 4,874 samples, 187 out of 207 replicated at a significance level of $p$ $<0.05$. The results did not vary significantly across differing ancestry groupings, except for seven DMPs where very strong population variation between Asian and European was seen (heterogeneity $p<1 \times 10^{-7}$ ), hinting at populationspecific or uncaptured genetic effects. All the changes were identified to be the potential consequence of obesity not causative, except for $1 \mathrm{CpG}$ (cg26663590) in NFATC2IP. These results were strongly enriched for methylation scores within an intermediate level of $20-80 \%$. This could point towards variation between certain cell subsets driving the signal, although analysis of 4 sub-fractions, monocytes, neutrophils, $C D 4^{+}$and $C D 8^{+} \mathrm{T}$ cells indicated that these results could in fact be seen across all these cell-types. Thus they differ from the biologically defined tobacco smoking results where cell-type specific divergent myeloid versus lymphoid signals could be found (58). A longitudinal sample set of 1,435 participants was evaluated over a period of seven years, showing a consistent relationship between change in methylation and change in BMI overtime in 178 of $187 \mathrm{CpGs}$. 
Another large-scale BMI EWAS was recently reported by Mendelson et al., again using the 450k array in peripheral blood (78). The discovery set was in those of predominately European ancestry, including individuals from the Lothian Birth Cohort in Scotland and the US Framingham Heart Study. 135 CpGs were initially identified as BMI-DMPs. 83 DMPs replicated in at least one of the 3 additional replication cohorts, ARIC ( $n=2,096)$, GOLDN ( $n=992)$, and PIVUS ( $\mathrm{n}=$ 967).

Gene ontology enrichment was identified for lipid metabolism in those DNA methylation variation associated genes that also had concordant expression changes. 77 of the CpGs that were non-redundant (i.e. correlation $|r|<0.7)$ captured $\sim 18 \%$ of the inter-individual variation in BMI. The previous HIF3A result replicated, with the strongest association seen in the youngest subset (cg22891070, $p=0.003$ ). Just 11 CpGs revealed a recognised threeway association whereby the DNA methylation was associated with BMI and expression, as well as BMl-associated expression changes. These included ABCG1, CACNA2D3, CPTIA (79), DHCR24, SARS, SLC1A5 and SREBF1. No enrichment for blood or adipose-specific regulatory features was seen using eFORGE (80) to detect tissue-specificity of the DMPs through co-localisation with tissue-specific DNase-I Hypersensitivity Sites. DMPs were more enriched in enhancer regions ( $\mathrm{H} 3 \mathrm{Kmel}$ ) than promoter, although this may indicate the less dynamic nature of these promoter CpGs (81). The top cis-mQTL for the replicated BMI-DMPs, selected by lowest $p$-value $\pm 500 \mathrm{~kb}$ from the CpG, was not strongly attenuated by BMI association in 81 of the $83 \mathrm{CpGs}$. One gene, SREBF1 (Sterol regulatory element-binding transcription factor 1), a lipid metabolism transcription factor was proposed as possibly causal. It is known to induce conversion of acetyl-CoA to triglycerides thus promoting glycolysis, lipogenesis and adipogenesis. Also, a role in adiposity, insulin resistance, coronary artery disease, obesity-related dyslipidaemia is supported in model organism and human studies (78).

A comparison of the results from these three recent large EWAS studies $(72,77,78)$ identified ten CpGs that were robust and replicated within each as well as being common to all (See Table 1). These ten CpGs are located in ten unique genes, predominately within intragenic intronic loci and in almost half within CPG island shores. They also are generally supported in other BMI- 
related studies $(70,82-85)$. Gene ontology enrichment analysis via GREAT for these ten CpGs (compared with the 450k array probes as background) identified nominal significance of biological processes, such as regulation of cholesterol and lipids, human phenotypes including hyperlipidemia, and diseases of the hepatobilary system (Supplementary Table S1).

In fact, many of these same CPGs are associated with lipid-related traits from specific EWAS's performed for these measures, assumedly due to their relationship to the development of adiposity or downstream-induced epigenetic changes from BMI-associated altered blood lipid profiles. Four of the ten DMPs are significantly related to triglyceride (TG) levels in a recent study by Dekkers et al. (49), as well as in earlier and contemporary lipid studies (79, 86-89). Furthermore, four CpGs are related to glucose-related phenotypes in a study of Kriebel et al. (90). This clearly shows the power of EWAS to identify more precise biochemical phenotypes (38) and the benefit of closely examining the distinct biological changes associated with broad epidemiological measures, such as BMI. A number of these exact CpGs also are supported by additional studies in or related to BMI, such as an analyses in Arabs (84), Metabolic Syndrome (83), and hypertriglyceridemic waist in Mexican Americans (91). Of interest is that one of the CpGs, cg06192883, in MYO5C, was recently identified in an EWAS for the inflammatory marker CRP (45). Another, cg09349128, in CRELD2, is associated with Inflammatory Bowel Disease (92), which is known itself to be connected to lipid abnormalities (93). Two additional genes, LGALS3BP (Lectin galactoside-binding soluble 3 binding protein) and SBNO2 (strawberry notch homolog 2), were consistently identified across all 3 studies but represented by differing CpGs.

\section{EWAS ANALYSIS IN ADIPOSE TISSUE}

Agha et al. analysed adipose tissue with the 450k array and associated measures of adiposity obtained by dual-energy X-ray absorptiometryassessed android fat mass, android:gynoid fat ratio and trunk:limb fat ratio, as well as BMI (71). This was in 106 individuals (64\% women, 68\% white) after adjusting for smoking, race, and sex as well as reference-free adipose cellmixture effects. A gene focused analysis identified association with these 
adiposity traits including ANGPT2, AOC3, AQP7, CETP, LIPE, and SOD3. HIF3A was also explored and found to be positively associated with BMI at the same 3 CpGs as identified by Dick et al. (70)

Ronn et al. investigated age, $\mathrm{BMl}$ and $\mathrm{HbAlc}$ levels, all risk factor for disease, in both adipose tissue and blood DNA methylation (74). The DNA methylation ageing signals seen previously in ELOVL2, FHL2, KLF14, GLRA 1 in blood were identified in adipose. This study supported the HIF3A finding in adipose within females only and found $\mathrm{HbAlc}$ associations with 711 sites in adipose tissue. There was minimal overlap in signal between $\mathrm{HbAlc}$ and BMI or age.

A study of post gastric bypass DNA methylation variation in adipose tissue identified changes within genes associated with obesity by pre- and post-surgery weight-loss analysis (94). Both omental and subcutaneous adipose tissue were compared and these give further insight to the dramatic physiological changes that occur with the rapid post-operative weight loss.

\section{OBESITY AND AGEING ASSOCIATED CHANGES}

Horvath et al. observed that obesity accelerates the detected epigenetic ageing of the liver when assessed by the Horvath 'Epigenetic Clock', but interestingly not in the other tissue types tested, including blood, adipose tissue, or muscle (95). Obesity-related nonalcoholic fatty liver disease did not drive these hepatic changes. Although, it was postulated to be associated with obesity-driven liver comorbidities, including insulin resistance and hepatocellular carcinoma. The lack of changes in other tissues was hypothesized as due to liver-specific oxidative stress and also perhaps the suboptimal measure of obesity via BMI.

A study by Simpkin et al. identified that an accelerated epigenetic age measure at birth is also associated with a more rapid increase in BMI in childhood (96). Furthermore, obesity is proposed to contribute to the 'exposome' that influences epigenetic ageing, with increased BMI from young adulthood to middle age contributing to a greater age acceleration (97). In an analysis integrating blood derived ageing-related differentially 
methylated regions (DMRs) within GWAS associated regions, 3 were identified within loci for fasting glucose-related traits that interact with BMI (17).

\section{DEVELOPMENTAL AND IN UTERO INFLUENCES}

Critical windows may exist for environmental or intrauterine factors to impact on the epigenome, as it being defined, during early development (98). These early changes are proposed to have the ability to act as 'metastable epialleles' that then propagate through the all germ layers to effect all cell types (99). Although evidence for a role in DNA methylation in this process in human is not strong, the possibility for some repetitive elements such as SVAs (SINE-VNTR-Alu) to escape the global demethylation, subsequent reprogramming, and then be vulnerable to environmental influence cannot be excluded at this stage (14).

Epidemiological data has proposed that in utero exposure to underand overnutrition affects obesity risk in later life, potentially through epigenetic modifications (100). Several studies have explored this through the unique model of contrasting children born before or after maternal gastric bypass surgery. Guénard et al. compared DNA methylation from siblings born from 25 mothers adjusting for age and sex and puberty (101). Children born prior to the procedure possessed a significantly higher z-score BMI, as well as poorer insulin resistance values. Temporal DNA methylation variation was identified, although in blood and not adjusted for cell-type effects, but gene enrichment for glucose homeostasis and immune function was seen. However, more recent and powerful studies have not borne out the findings of these earlier studies. In a direct obesity analysis, Willmer et al. in a study from Scandinavia of 164 children born before and 176 born after surgery at four years of age did not show any improving effect of bariatric surgery on weight development in children (77). Sharp et al. examined 1,018 neonatal cord blood derived DNA methylomes with the 450k array for the relationship between maternal and later childhood adiposity. Both high and low maternal weight extremes were seen to led to significant neonatal epigenetic changes, although weight gain during pregnancy was not influential (102). A large Danish Birth cohort of 30,655 trio families examined children at seven 
years to also directly explore the influence of parental BMI through pregnancy. This supported a role for the intrauterine environment in fetal and child growth trajectories, but that later parent-child associations in weight were likely to be contributed to by shared known genetic or environmental factors with both parents (103).

The genetic component of these maternal adiposity epidemiological observations has been recently dissected through large-scale GWAS and was seen to be a significant, but not complete, contributor (104). Furthermore, Richmond et al. performed a direct MR analysis, using a weighted genetic score from variants for BMI, for maternal obesity influences in children from ages 7-18 years. In over 2,000 samples in both discovery and replication sets, they found little support for a strong causal intrauterine effect of increasing maternal BMI with increased childhood adiposity (105). The complexity of this MR analysis in this scenario was recently discussed by Lawlor et al. (106).

\section{LIMITATIONS AND FUTURE DIRECTIONS}

Current large-scale high-throughput analysis is limited to DNA methylation array-based techniques, commonly the 450k array and the more recent $850 \mathrm{k}$ array. These provide only a partial story with regards to the DNA methylome as $\sim 28$ million CpGs reside within the genome, as well as the additional potential for non-CG changes. An obvious area of underexploration by this approach is repetitive elements, which are proposed to conceal significant functionality, such as the strong overlap of chromatin enhancer evidence within LTR repeat class member LTRI2C (107). Examples also include a potential epigenetic role for an Alu repetitive element in POMC in childhood obesity (108).

Furthermore, co-ordinated variation across a functional region, such as an enhancer, by the delineation of a significant DMR can increase statistical and biological confidence of the result (109). However, sparse array data are not the most powerful for robust DMR calling (110). Enrichment for disease ontology based results is stronger using sequencing-derived DMRs rather than isolated DMPs (58). Thus, larger and more in depth sequencing-focused analyses could identify further novel findings. 
External confounding factors in EWAS analysis include tobacco, alcohol, diet, medications, and other chemicals (68), though these signatures are now beginning to be precisely defined. Strong and replicated effects from prenatal exposures with smoking that persist into childhood exist, although these are not yet robust for diet. However, evidence exists in a number of murine and other animal models which have explored prenatal dietary exposures (111). DNA methylation associations with blood serum metabolites have been identified in humans through EWAS (112).

Major areas for future exploration are the influence of rare cell types, and an issue not yet resolved in biology, at what point does a change in the epigenome of a cell then indicate a new cell type? Epigenetic variability is occurring even in assumed homogenous cell-types, such as neutrophils (113). It is of important note that when robustly controlled experiments reduce genetic and cell-type variability by the use of isolated cell-types in MZ twin discordant models, minimal significant directional disease-associated DMPs are identified (39). Although, increased variability at distinct positions can be found, it is not attributable therefore could be technical artefact, or unaccounted environmental effects. Underlining these cell-type specific effects, the Mendelson et al. BMI EWAS only saw 22 of the initial 135 DMPs replicated in isolated $\mathrm{CD}^{+}{ }^{+} \mathrm{T}$ cells (78). Validation and most crucially independent replication are required for robust findings to be reported, with subsequent functional investigation in appropriate biological models.

The integration of genetic and epigenetic data is another area where powerful insights can be made. Analysis within GWAS loci to determine allelic or haplotype epigenetic differences was first shown with DNA methylation in the obesity-related FTO locus (31). This amalgamation of epigenetic and haplotypic data has now become a valuable tool in the dissection of GWAS traits (114). Incorporating chromatin segmentation data across multiple tissue types, including fat, enabled the localisation of enhancer variation in adipocytes influencing IRX3 and IRX5 expression, within the large linkage disequilibrium (LD) block region of FTO. These regulatory genes were shown to be involved with the browning of fat and thermogenesis (115).

Few studies to date have analysed histone variants or post-translational modifications with respect to human obesity, and have been limited to 
extremely small numbers and/or only global measures (116). Murine studies have proposed potential biological insights that may merit human exploration, such as histone variant MacroH2A1, which may have an antiadipogenic role within differentiating adipose tissue (117). However, largescale human studies are on the horizon, as can be seen by the example of a recent successful post-mortem study for Autism Spectrum Disorder in the brain of the active chromatin mark H3K27ac, or Histone Acetylome-wide Association Study (HAWAS) (118). Also, the use of Histone Deacetylase Inhibitors in inflammation-related diseases, as well the potential of targeted epigenetic drugs via CRISPR, point to future epigenomic therapeutic possibilities (119).

\section{CONCLUSION}

Epigenomic analysis is a significant tool in the hunt to improve risk prediction, as well as prognosis, beyond the rudimentary measure of BMI for obesity-related diseases. By observing at a molecular level the biologically perturbed mechanisms associated with this disorder, we may understand more precisely, for instance, the significant pathogenic influence of visceral fat. On the epidemiological side, whilst population-based strategies have borne the greatest improvements in human health in the past, there is now evidence that this may not be the case for obesity (120). More focused policies may be required due to its widening distribution over time.

Large-scale DNA methylation array analyses in blood have revealed the precise sequelae of the obese state, such as epigenetic changes driven by dyslipidemia, hyperglycaemia and chronic inflammation. This points towards the use of more precisely defined biochemical phenotypes in EWAS analysis. Nevertheless, further study may implicate additional novel diseaseassociated outcomes, exposures or even causes. These could include or exclude unproven but intriguingly proposed factors, such as air pollution (121), metal exposure (122), or other "obesogens" in the environment and food chain (123), with a role in obesity, or other diseases. The powerful potential of robustly identified DNA methylation biomarkers, even if not causal, can be seen for tobacco-associated AHRR cg05575921 capturing 
future smoking-related morbidity and mortality (124). With regards to obesity, potential to predict future cardiovascular disease exists in the lipid-related DNA methylation changes that influence ABCG 1 expression (125).

The analysis of the epigenome is constantly improving and being refined, such as recent discussion by van Iterson et al. on controlling genomic bias in DNA methylation EWAS (69). This trajectory will enable us to more accurately define the epigenome and interpret these findings. Increased high-throughput access to distal regulatory regions via the 850k array, larger sample-sized sequencing-based DNA methylome studies, and the analysis of additional modifications, including population chromatin data, will drive forward this progress. Also, the potential of 3rd generation sequencing to directly assess DNA modifications will be a significant step for epigenomics (126). We will be able to more accurately define currently abstractly lumped together 'environmental' change, by more precisely excluding or integrating genetic effects, as well as defining cell-type specific and cell proportion changes, including increasingly rare cell-types. With this will come improved biological interpretation and understanding of critical pathological changes within defined cell-type(s), and genetic pathways. This knowledge will hopefully help reduce the chronic burden of obesity worldwide. 


\section{FIGURE LEGEND}

Figure 1 - Factors influencing DNA methylation array analysis A: Direct CpGSNPS; B: SNPS under probe sequences. C: Cis and Trans SNP effects with increased (orange) or decreased (grey) transcription factor (TF) expression influencing the methylation state of binding site; D: Cis effects can include regional effects from Hypermethylated Repeats or Methylation Determining Region motifs within $\mathrm{CPG}$ dense regions; E: Density change within Intermediate CPG density regions such as CPG Island shores will also influence methylation state. 


\section{TABLE}

\begin{tabular}{|c|c|c|c|c|c|c|c|c|c|}
\hline chr & start & Stop & CpG & Gene & $\begin{array}{l}\text { Methyl } \\
\text { BMI }\end{array}$ & CGI & Location & $\begin{array}{l}\text { Additional } \\
\text { BMI }\end{array}$ & $\begin{array}{l}\text { Other } \\
\text { Phenotype }\end{array}$ \\
\hline chrll & 68607621 & 68607622 & $\begin{array}{l}\text { cg0057495 } \\
8\end{array}$ & CPTIA & - & Shore & Intronic & $\begin{array}{l}\text { BMI \& } \\
\text { WC* (82); }\end{array}$ & $\begin{array}{l}\text { TG(49,86, 87); } \\
\text { VLDL-C(87); } \\
\text { Lipoprotein } \\
\text { Subfractions(7 } \\
\text { 9); HTG } \\
\text { waist(91); MetS } \\
\text { in Eur(83) }\end{array}$ \\
\hline chrl5 & 52554170 & 52554171 & $\begin{array}{l}\operatorname{cg} 0619288 \\
3\end{array}$ & MYO5C & + & - & Intronic & $\begin{array}{l}\text { BMl in } \\
\text { Arab (84) }\end{array}$ & CRP (45) \\
\hline chr21 & 43656586 & 43656587 & $\begin{array}{l}\text { cg0650016 } \\
1\end{array}$ & $A B C G 1$ & + & Shore & Intronic & & $\begin{array}{l}\text { TG, HDL-C (49, } \\
88,89) ; \\
\text { Glucose- } \\
\text { related }(90) ; \\
\text { HTG waist }(91)\end{array}$ \\
\hline chrlo & 11422408 & 11422409 & $\begin{array}{l}\text { cg0694679 } \\
7\end{array}$ & RMI2 & - & - & Intronic & $\begin{array}{l}\text { BMl in } \\
\text { Arab (84) }\end{array}$ & $\begin{array}{l}\text { Glucose- } \\
\text { related }(90)\end{array}$ \\
\hline Chrl7 & 40927698 & 40927699 & $\begin{array}{l}\text { cg0885779 } \\
7\end{array}$ & VPS25 & + & - & Intronic & $\begin{array}{l}\text { BMl in } \\
\text { Arab (84) }\end{array}$ & TG(49) \\
\hline chr22 & 50327985 & 50327986 & $\begin{array}{l}\text { cg0934912 } \\
8\end{array}$ & CRELD2 & - & Shore & $\begin{array}{l}\text { Intergeni } \\
\mathrm{C}\end{array}$ & & $\begin{array}{l}\text { Glucose- } \\
\text { related(90); } \\
\text { IBD(92) }\end{array}$ \\
\hline chrl7 & 2612405 & 2612406 & $\begin{array}{l}\text { cg09666444 } \\
5\end{array}$ & CLUH & + & Shore & Intronic & $\begin{array}{l}\text { BMl in } \\
\text { Arab (84); } \\
\text { \& in Eur(70) }\end{array}$ & \\
\hline chrl7 & 17730093 & 17730094 & $\begin{array}{l}\operatorname{cg} 1102468 \\
2\end{array}$ & SREBF 1 & + & Shelf & Intronic & $\begin{array}{l}\text { BMl in } \\
\text { Eur(85) }\end{array}$ & $\begin{array}{l}\text { TG }(49,89) \\
\text { Glucose- } \\
\text { related }(90)\end{array}$ \\
\hline chr6 & 31681881 & 31681882 & $\begin{array}{l}\operatorname{cg} 1312300 \\
9\end{array}$ & LYGG6F & + & - & Intronic & $\begin{array}{l}\text { BMl in } \\
\text { Arab (84) }\end{array}$ & \\
\hline chr5 & $\begin{array}{l}15863408 \\
4\end{array}$ & $\begin{array}{l}15863408 \\
5\end{array}$ & $\begin{array}{l}\text { cg2640384 } \\
3\end{array}$ & RNFI45 & + & Shelf & Intronic & & \\
\hline
\end{tabular}

Table 1: Consistent BMI-DMPs from the studies of Demerath et al. (72), Wahl et al. (77), and Mendelson et al. (78).

WC: Waist circumference, TG: Triglycerides; LDL-C: Low Density Lipoprotein Cholesterol; HDL-C: Low Density Lipoprotein Cholesterol; VLDL-C: Very Low Density Lipoprotein Cholesterol; HTG: Hypertriglyceridemic.

*This study was in fact performed earlier with many of the same cohorts at Wahl et al. 


\section{APPENDIX}

cis-regulatory elements $=$ binding sites of transcription factors that enhance or repress transcription.

CPG-SNP = SNP that creates or abrogates a CpG dinucleotide

CTCF = CCCTC-binding factor transcription factor

DMP - Differentially Methylated Position

DMR - Differentially Methylated Region

EWAS - Epigenome-Wide Association study

GWAS - Genome-wide Association study

$\mathrm{LD}=$ Linkage Disequilibrium

LTR $=$ Long Terminal Repeats

$M D R=$ Methylation Determining Regions

$\mathrm{mQTL}=$ methylation Quantitative Trait Loci

$M R=$ Mendelian Randomisation

RFX = regulatory factor $X$ family transcription factor

SNP $=$ Single Nucleotide Polymorphism

SVA = SINE-VNTR-Alu repeat element

trans-regulatory elements = DNA sequences that encode transcription factors

\section{CONFLICT OF INTEREST STATEMENT}

The author declares no conflict of interest

\section{SUPPLEMENTARY TABLE S1}

Gene Enrichment Analysis for 10 Consistent BMI-associated CpGs 


\section{REFERENCES}

1. Zhou VW, Goren A, Bernstein BE. Charting histone modifications and the functional organization of mammalian genomes. Nature reviews Genetics. 2011;12(1):7-18. Epub 2010/12/01. doi: 10.1038/nrg2905. PubMed PMID: 21116306. 2. Reddon H, Gueant JL, Meyre D. The importance of gene-environment interactions in human obesity. Clinical science (London, England: 1979). 2016;130(18):1571-97. Epub 2016/08/10. doi: 10.1042/cs20160221. PubMed PMID: 27503943.

3. Young Al, Wauthier F, Donnelly P. Multiple novel gene-by-environment interactions modify the effect of FTO variants on body mass index. Nat Commun. 2016;7:12724. Epub 2016/09/07. doi: 10.1038/ncomms12724. PubMed PMID: 27596730; PubMed Central PMCID: PMCPMC5025863.

4. Bray GA, Fruhbeck G, Ryan DH, Wilding JP. Management of obesity. Lancet. 2016;387(10031):1947-56. doi: 10.1016/S0140-6736(16)00271-3. PubMed PMID: 26868660 .

5. Heymsfield SB, Wadden TA. Mechanisms, Pathophysiology, and Management of Obesity. New England Journal of Medicine. 2017;376(3):254-66. doi:

doi:10.1056/NEJMra1514009. PubMed PMID: 28099824.

6. Kitahara CM, Flint AJ, Berrington de Gonzalez A, Bernstein L, Brotzman M, Maclnnis RJ, et al. Association between Class III Obesity (BMI of 40-59 kg/m2) and Mortality: A Pooled Analysis of 20 Prospective Studies. PLOS Medicine.

2014;11 (7):e1001673. doi: 10.1371/journal.pmed.1001673.

7. Maze I, Noh KM, Soshnev AA, Allis CD. Every amino acid matters: essential contributions of histone variants to mammalian development and disease. Nat Rev Genet. 2014;15(4):259-71. doi: 10.1038/nrg3673. PubMed PMID: 24614311; PubMed Central PMCID: PMCPMC4082118.

8. Branco MR, Ficz G, Reik W. Uncovering the role of 5-hydroxymethylcytosine in the epigenome. Nat Rev Genet. 2012;13(1):7-13. Epub 2011/11/16. doi:

10.1038/nrg3080. PubMed PMID: 22083101.

9. Hon Gary C, Song C-X, Du T, Jin F, Selvaraj S, Lee Ah Y, et al. 5 mC Oxidation by Tet2 Modulates Enhancer Activity and Timing of Transcriptome Reprogramming during Differentiation. Molecular Cell. 2014;56(2):286-97. doi:

http://dx.doi.org/10.1016/i.molcel.2014.08.026.

10. consortium B. Quantitative comparison of DNA methylation assays for biomarker development and clinical applications. Nat Biotechnol. 2016;34(7):726-37. doi: 10.1038/nbt.3605. PubMed PMID: 27347756.

11. Greally JM. Population Epigenetics. Current Opinion in Systems Biology. 2017. doi: http://dx.doi.org/10.1016/j.coisb.2017.01.004.

12. O'Rahilly S. Human genetics illuminates the paths to metabolic disease. Nature. 2009:462(7271):307-14. Epub 2009/11/20. doi: nature08532 [pii] 10.1038/nature08532. PubMed PMID: 19924209.

13. Bell CG, Walley AJ, Froguel P. The genetics of human obesity. Nature reviews Genetics. 2005;6(3):221-34. Epub 2005/02/11. doi: 10.1038/nrg1556. PubMed PMID: 15703762.

14. Tang WW, Kobayashi T, Irie N, Dietmann S, Surani MA. Specification and epigenetic programming of the human germ line. Nat Rev Genet. 2016;17(10):585600. doi: 10.1038/nrg.2016.88. PubMed PMID: 27573372.

15. Feil R, Fraga MF. Epigenetics and the environment: emerging patterns and implications. Nature reviews Genetics. 201 1;13(2):97-109. Epub 2012/01/05. doi: 10.1038/nrg3142. PubMed PMID: 22215131.

16. Teschendorff AE, Menon U, Gentry-Maharaj A, Ramus SJ, Weisenberger DJ, Shen $\mathrm{H}$, et al. Age-dependent DNA methylation of genes that are suppressed in stem cells is a hallmark of cancer. Genome Res. 2010;20(4):440-6. Epub 2010/03/12. doi: gr.103606.109 [pii] 
10.1101/gr.103606.109. PubMed PMID: 20219944; PubMed Central PMCID: PMC2847747.

17. Bell CG, Xia Y, Yuan W, Gao F, Ward K, Roos L, et al. Novel regional ageassociated DNA methylation changes within human common disease-associated loci. Genome Biol. 2016;17(1):193. Epub 2016/09/25. doi: 10.1186/s13059-016-1051-8. PubMed PMID: 27663977.

18. Schalkwyk LC, Meaburn EL, Smith R, Dempster EL, Jeffries AR, Davies MN, et al. Allelic skewing of DNA methylation is widespread across the genome. Am J Hum Genet. 2010;86(2):196-212. Epub 2010/02/18. doi: S0002-9297(10)00017-0 [pii] 10.1016/j.ajhg.2010.01.014. PubMed PMID: 20159110.

19. Shoemaker R, Deng J, Wang W, Zhang K. Allele-specific methylation is prevalent and is contributed by CpG-SNPs in the human genome. Genome Res. 2010;20(7):883-9. Epub 2010/04/27. doi: gr.104695.109 [pii] 10.1101/gr.104695.109. PubMed PMID: 20418490.

20. Heintzman ND, Ren B. Finding distal regulatory elements in the human genome. Curr Opin Genet Dev. 2009;19(6):541-9. Epub 2009/10/27. doi: 10.1016/j.gde.2009.09.006. PubMed PMID: 19854636; PubMed Central PMCID: PMCPMC3321269.

21. Richards EJ. Inherited epigenetic variation--revisiting soft inheritance. Nat Rev Genet. 2006;7(5):395-401. Epub 2006/03/15. doi: nrg1834 [pii] 10.1038/nrg1834. PubMed PMID: 16534512.

22. Brandeis M, Frank D, Keshet I, Siegfried Z, Mendelsohn M, Nemes A, et al. Spl elements protect a $\mathrm{CPG}$ island from de novo methylation. Nature. 1994;371 (6496):435-8. Epub 1994/09/29. doi: 10.1038/371435a0. PubMed PMID: 8090226.

23. Lienert F, Wirbelaver C, Som I, Dean A, Mohn F, Schubeler D. Identification of genetic elements that autonomously determine DNA methylation states. Nature genetics. 2011;43(11):1091-7. Epub 2011/10/04. doi: 10.1038/ng.946. PubMed PMID: 21964573.

24. Stadler MB, Murr R, Burger L, Ivanek R, Lienert F, Scholer A, et al. DNA-binding factors shape the mouse methylome at distal regulatory regions. Nature.

2011;480(7378):490-5. Epub 2011/12/16. doi: 10.1038/nature10716. PubMed PMID: 22170606 .

25. Domcke S, Bardet AF, Adrian Ginno P, Hartl D, Burger L, Schubeler D. Competition between DNA methylation and transcription factors determines binding of NRF1. Nature. 2015;528(7583):575-9. Epub 2015/12/18. doi: 10.1038/nature 16462. PubMed PMID: 26675734.

26. Yin Y, Morgunova E, Jolma A, Kaasinen E, Sahu B, Khund-Sayeed S, et al. Impact of cytosine methylation on DNA binding specificities of human transcription factors. Science. 2017;356(6337). doi: 10.1126/science.aaj2239.

27. Bonder MJ, Luijk R, Zhernakova DV, Moed M, Deelen P, Vermaat $M$, et al. Disease variants alter transcription factor levels and methylation of their binding sites. Nat Genet. 2017:49(1):131-8. doi: 10.1038/ng.3721. PubMed PMID: 27918535.

28. Kasowski M, Kyriazopoulou-Panagiotopoulou S, Grubert F, Zaugg JB, Kundaje A, Liu $Y$, et al. Extensive variation in chromatin states across humans. Science. 2013;342(6159):750-2. doi: 10.1 126/science.1242510. PubMed PMID: 24136358; PubMed Central PMCID: PMC4075767.

29. Grandi FC, Rosser JM, Newkirk SJ, Yin J, Jiang X, Xing Z, et al. Retrotransposition creates sloping shores: a graded influence of hypomethylated CpG islands on flanking CpG sites. Genome Res. 2015;25(8):1 135-46. Epub 2015/05/23. doi: 10.1101/gr.185132.114. PubMed PMID: 25995269; PubMed Central PMCID: PMCPMC4509998.

30. Schubeler D. Function and information content of DNA methylation. Nature. 2015;517(7534):321-6. doi: 10.1038/nature14192.

31. Bell CG, Finer S, Lindgren CM, Wilson GA, Rakyan VK, Teschendorff AE, et al. Integrated Genetic and Epigenetic Analysis Identifies Haplotype-Specific Methylation 
in the FTO Type 2 Diabetes and Obesity Susceptibility Locus. PLoS One. 2010;5(11):el4040. Epub 2010/12/03. doi: 10.1371/journal.pone.0014040. PubMed PMID: 21124985.

32. Gibbs JR, van der Brug MP, Hernandez DG, Traynor BJ, Nalls MA, Lai SL, et al. Abundant quantitative trait loci exist for DNA methylation and gene expression in human brain. PLoS Genet. 2010;6(5):e1000952. Epub 2010/05/21. doi: 10.1371/journal.pgen.1000952. PubMed PMID: 20485568; PubMed Central PMCID: PMC2869317.

33. Liu Y, Li X, Aryee Martin J, Ekström Tomas J, Padyukov L, Klareskog L, et al. GeMes, Clusters of DNA Methylation under Genetic Control, Can Inform Genetic and Epigenetic Analysis of Disease. The American Journal of Human Genetics. 2014;94. doi: 10.1016/j.ajhg.2014.02.011.

34. Wilson GA, Butcher LM, Foster HR, Feber A, Roos C, Walter L, et al. Humanspecific epigenetic variation in the immunological Leukotriene B4 Receptor (LTB4R/BLT1) implicated in common inflammatory diseases. Genome Med. 2014;6(3):19. Epub 2014/03/07. doi: 10.1186/gm536. PubMed PMID: 24598577. 35. Heijmans BT, Mill J. Commentary: The seven plagues of epigenetic epidemiology. Int J Epidemiol. 2012;41 (1):74-8. Epub 2012/01/25. doi: 10.1093/ije/dyr225. PubMed PMID: 22269254; PubMed Central PMCID: PMC3304528. 36. Birney E, Smith GD, Greally JM. Epigenome-wide Association Studies and the Interpretation of Disease -Omics. PLoS Genet. 2016;12(6):e1006105. doi:

10.1371/journal.pgen.1006105. PubMed PMID: 27336614; PubMed Central PMCID: PMCPMC4919098.

37. Gregor MF, Hotamisligil GS. Inflammatory mechanisms in obesity. Annual review of immunology. 2011 ;29:415-45. doi: 10.1146/annurev-immunol-031210-101322. PubMed PMID: 21219177.

38. Houseman EA, Kim S, Kelsey KT, Wiencke JK. Dna methylation in whole blood: Uses and challenges. Curr Environ Health Rep. 2015;2. doi: 10.1007/s40572-015-0050-3.

39. Paul DS, Teschendorff AE, Dang MA, Lowe R, Hawa MI, Ecker S, et al. Increased DNA methylation variability in type 1 diabetes across three immune effector cell types. Nat Commun. 2016;7:13555. Epub 2016/11/30. doi: 10.1038/ncomms13555. PubMed PMID: 27898055.

40. McGregor K, Bernatsky S, Colmegna I, Hudson M, Pastinen T, Labbe A, et al. An evaluation of methods correcting for cell-type heterogeneity in DNA methylation studies. Genome Biology. 2016;17:84. doi: 10.1 186/s13059-016-0935-y. PubMed PMID: PMC4855979.

41. Roadmap Epigenomics C, Kundaje A, Meuleman W, Ernst J, Bilenky M, Yen A, et al. Integrative analysis of 111 reference human epigenomes. Nature.

2015;518(7539):317-30. doi: 10.1038/nature14248

http://www.nature.com/nature/journal/v518/n7539/abs/nature14248.html supplementary-information.

42. The Bc. Quantitative comparison of DNA methylation assays for biomarker development and clinical applications. Nat Biotech. 2016; advance online publication. doi: 10.1038/nbt.3605

http://www.nature.com/nbt/journal/vaop/ncurrent/abs/nbt.3605.html supplementary-information.

43. Tanay A, Regev A. Scaling single-cell genomics from phenomenology to mechanism. Nature. 2017;541 (7637):331-8. Epub 2017/01/20. doi:

10.1038/nature21350. PubMed PMID: 28102262.

44. Kim S, Eliot M, Koestler DC, Houseman EA, Wetmur JG, Wiencke JK, et al. Enlarged leukocyte referent libraries can explain additional variance in blood-based epigenome-wide association studies. Epigenomics. 2016;8(9):1185-92.

45. Ligthart S, Marzi C, Aslibekyan S, Mendelson MM, Conneely KN, Tanaka T, et al. DNA methylation signatures of chronic low-grade inflammation are associated with complex diseases. Genome Biology. 2016;17(1):255. doi: 10.1 186/s13059-016-1119-5. 
46. Rimmelé P, Bigarella Carolina L, Liang R, Izac B, Dieguez-Gonzalez R, Barbet G, et al. Aging-like Phenotype and Defective Lineage Specification in SIRT1-Deleted Hematopoietic Stem and Progenitor Cells. Stem Cell Reports. 2014;3(1):44-59. doi: http://dx.doi.org/10.1016/j.stemcr.2014.04.015.

47. Hernandez DG, Nalls MA, Gibbs JR, Arepalli S, van der Brug M, Chong S, et al. Distinct DNA methylation changes highly correlated with chronological age in the human brain. Hum Mol Genet. 2011 ;20(6):1 164-72. doi: 10.1093/hmg/ddq561. PubMed PMID: 21216877; PubMed Central PMCID: PMCPMC3043665.

48. Houseman EA. DNA Methylation and Cell-Type Distribution. Computational and Statistical Epigenomics: Springer; 2015. p. 35-50.

49. Dekkers KF, van Iterson M, Slieker RC, Moed MH, Bonder MJ, van Galen M, et al. Blood lipids influence DNA methylation in circulating cells. Genome Biol. 2016;17(1):138. doi: 10.1 186/s13059-016-1000-6. PubMed PMID: 27350042; PubMed Central PMCID: PMCPMC4922056.

50. Rakyan VK, Beyan H, Down TA, Hawa MI, Maslau S, Aden D, et al. Identification of type 1 diabetes-associated DNA methylation variable positions that precede disease diagnosis. PLoS genetics. 201 1;7(9):e1002300. Epub 2011/10/08. doi: 10.1371/journal.pgen.1002300. PubMed PMID: 21980303; PubMed Central PMCID: PMC3183089.

51. Roos L, Spector TD, Bell CG. Using epigenomic studies in monozygotic twins to improve our understanding of cancer. Epigenomics. 2014;6(3):299-309. Epub 2014/08/12. doi: 10.2217/epi.14.13. PubMed PMID: 25111484.

52. Andrews SV, Ladd-Acosta C, Feinberg AP, Hansen KD, Fallin MD. "Gap hunting" to characterize clustered probe signals in llumina methylation array data. Epigenetics \& chromatin. 2016;9:56. Epub 2016/12/17. doi: 10.1186/s13072-016-0107-z. PubMed PMID: 27980682; PubMed Central PMCID: PMCPMC5142147.

53. Chen Y-a, Lemire M, Choufani S, Butcher DT, Grafodatskaya D, Zanke BW, et al. Discovery of cross-reactive probes and polymorphic CpGs in the Illumina Infinium HumanMethylation450 microarray. Epigenetics. 2013;8(2):203-9. doi: 10.4161/epi.23470. PubMed PMID: PMC3592906.

54. Chen L, Ge B, Casale Francesco P, Vasquez L, Kwan T, Garrido-Martín D, et al. Genetic Drivers of Epigenetic and Transcriptional Variation in Human Immune Cells. Cell. 2016;167(5):1398-414.e24. doi: 10.1016/j.cell.2016.10.026.

55. Dayeh T, Volkov P, Salo S, Hall E, Nilsson E, Olsson AH, et al. Genome-wide DNA methylation analysis of human pancreatic islets from type 2 diabetic and nondiabetic donors identifies candidate genes that influence insulin secretion. PLOS Genet. 2014;10(3):e1004160. doi: 10.1371/journal.pgen.1004160. PubMed PMID: 24603685; PubMed Central PMCID: PMCPMC3945174.

56. Olsson AH, Volkov P, Bacos K, Dayeh T, Hall E, Nilsson EA, et al. Genome-wide associations between genetic and epigenetic variation influence mRNA expression and insulin secretion in human pancreatic islets. PLoS Genet. 2014;10(11):e1004735. doi: 10.1371/journal.pgen.1004735. PubMed PMID: 25375650; PubMed Central PMCID: PMCPMC4222689.

57. McClay JL, Shabalin AA, Dozmorov MG, Adkins DE, Kumar G, Nerella S, et al. High density methylation QTL analysis in human blood via next-generation sequencing of the methylated genomic DNA fraction. Genome Biol. 2015;16(1):291. doi: 10.1 186/s13059-015-0842-7. PubMed PMID: 26699738; PubMed Central PMCID: PMC4699364.

58. Su D, Wang X, Campbell MR, Porter DK, Pittman GS, Bennett BD, et al. Distinct Epigenetic Effects of Tobacco Smoking in Whole Blood and among Leukocyte Subtypes. PLOS ONE. 2016;1 1 (12):e0166486. doi: 10.1371/journal.pone.0166486. 59. Baver M, Linsel G, Fink B, Offenberg K, Hahn AM, Sack U, et al. A varying T cell subtype explains apparent tobacco smoking induced single CpG hypomethylation in whole blood. Clinical epigenetics. 2015;7(1):81. doi: 10.1186/s13148-015-0113-1.

PubMed PMID: 26246861; PubMed Central PMCID: PMC4526203. 
60. Grant RW, Dixit VD. Adipose tissue as an immunological organ. Obesity (Silver Spring, Md). 2015;23(3):512-8. doi: 10.1002/oby.21003. PubMed PMID: PMC4340740.

61. Huh JY, Park YJ, Ham M, Kim JB. Crosstalk between Adipocytes and Immune Cells in Adipose Tissue Inflammation and Metabolic Dysregulation in Obesity. Molecules and Cells. 2014;37(5):365-71. doi: 10.14348/molcells.2014.0074. PubMed PMID: PMC4044307.

62. Rosen ED, Spiegelman BM. What we talk about when we talk about fat. Cell. 2014;156(1-2):20-44. Epub 2014/01/21. doi: 10.1016/j.cell.2013.12.012. PubMed PMID: 24439368; PubMed Central PMCID: PMCPMC3934003.

63. Emdin CA, Khera AV, Natarajan P, et al. Genetic association of waist-to-hip ratio with cardiometabolic traits, type 2 diabetes, and coronary heart disease. JAMA. 2017;317(6):626-34. doi: 10.1001/jama.2016.21042.

64. Hotamisligil GS. Inflammation, metaflammation and immunometabolic disorders. Nature. 2017;542(7640):177-85. doi: 10.1038/nature21363 http://www.nature.com/nature/journal/v542/n7640/abs/nature21363.html supplementary-information.

65. Wensveen FM, Jelencic $V$, Valentic $S$, Sestan $M$, Wensveen $T T$, Theurich $S$, et al. NK cells link obesity-induced adipose stress to inflammation and insulin resistance. Nat Immunol. 2015;16(4):376-85. doi: 10.1038/ni.3120. PubMed PMID: 25729921.

66. Wiencke JK, Butler R, Hsuang G, Eliot M, Kim S, Sepulveda MA, et al. The DNA methylation profile of activated human natural killer cells. Epigenetics. 2016;1 1 (5):36380. doi: 10.1080/15592294.2016.1 163454. PubMed PMID: 26967308; PubMed Central PMCID: PMCPMC4889279.

67. Bell CG. Epigenomic Factors in Human Obesity. 1st ed. Tollefsbol TO, editor. Amsterdam ; Boston: Elsevier/AP; 20122012.

68. van Dijk SJ, Molloy PL, Varinli H, Morrison JL, Muhlhausler BS. Epigenetics and human obesity. Int J Obes (Lond). 2015;39(1):85-97. Epub 2014/02/26. doi:

10.1038/ijo.2014.34. PubMed PMID: 24566855.

69. van Iterson M, van Zwet EW, Consortium B, Heijmans BT. Controlling bias and inflation in epigenome- and transcriptome-wide association studies using the empirical null distribution. Genome Biol. 2017;18(1):19. doi: 10.1 186/s13059-016-1131-9. PubMed PMID: 28129774; PubMed Central PMCID: PMCPMC5273857.

70. Dick KJ, Nelson CP, Tsaprouni L, Sandling JK, Aissi D, Wahl S, et al. DNA methylation and body-mass index: a genome-wide analysis. Lancet. 2014;383(9933):1990-8. Epub 2014/03/19. doi: 10.1016/s0140-6736(13)62674-4. PubMed PMID: 24630777.

71. Agha G, Houseman EA, Kelsey KT, Eaton CB, Buka SL, Loucks EB. Adiposity is associated with DNA methylation profile in adipose tissue. Int J Epidemiol. 2015;44(4):1277-87. doi: 10.1093/ije/dyu236. PubMed PMID: PMC4588857.

72. Demerath EW, Guan W, Grove ML, Aslibekyan S, Mendelson M, Zhou YH, et al. Epigenome-wide association study (EWAS) of BMI, BMI change and waist circumference in African American adults identifies multiple replicated loci. Hum Mol Genet. 2015;24(15):4464-79. Epub 2015/05/03. doi: 10.1093/hmg/ddv161. PubMed PMID: 25935004; PubMed Central PMCID: PMCPMC4492394.

73. Huang T, Zheng Y, Qi Q, XU M, Ley SH, Li Y, et al. DNA Methylation Variants at HIF3A Locus, B-Vitamin Intake, and Long-term Weight Change: Gene-Diet Interactions in Two U.S. Cohorts. Diabetes. 2015;64(9):3146-54. Epub 2015/05/24. doi: 10.2337/db150264. PubMed PMID: 26001398; PubMed Central PMCID: PMCPMC4542450.

74. Rönn T, Volkov P, Gillberg L, Kokosar M, Perfilyev A, Jacobsen AL, et al. Impact of age, BMl and $\mathrm{HbAlc}$ levels on the genome-wide DNA methylation and mRNA expression patterns in human adipose tissue and identification of epigenetic biomarkers in blood. Human Molecular Genetics. 2015;24(13):3792-813. doi: $10.1093 / \mathrm{hmg} / \mathrm{ddv} 124$.

75. Richmond RC, Sharp GC, Ward ME, Fraser A, Lyttleton O, McArdle WL, et al. DNA Methylation and BMI: Investigating Identified Methylation Sites at HIF3A in a 
Causal Framework. Diabetes. 2016;65(5):1231-44. doi: 10.2337/db15-0996. PubMed PMID: 26861784; PubMed Central PMCID: PMCPMC483921 1.

76. Main AM, Gillberg L, Jacobsen AL, Nilsson E, Gjesing AP, Hansen T, et al. DNA methylation and gene expression of HIF3A: cross-tissue validation and associations with BMI and insulin resistance. Clinical epigenetics. 2016;8:89. Epub 2016/09/07. doi: 10.1 186/s131 48-016-0258-6. PubMed PMID: 27594926; PubMed Central PMCID: PMCPMC5010678.

77. Willmer $M$, Berglind D, Sørensen TIA, Näslund E, Tynelius P, Rasmussen F. Surgically Induced Interpregnancy Weight Loss and Prevalence of Overweight and Obesity in Offspring. PLOS ONE. 2013;8(12):e82247. doi: 10.1371/journal.pone.0082247. 78. Mendelson MM, Marioni RE, Joehanes R, Liu C, Hedman AK, Aslibekyan S, et al. Association of Body Mass Index with DNA Methylation and Gene Expression in Blood Cells and Relations to Cardiometabolic Disease: A Mendelian Randomization Approach. PLoS Med. 2017;14(1):e1002215. Epub 2017/01/18. doi:

10.1371/journal.pmed.1002215. PubMed PMID: 28095459.

79. Frazier-Wood AC, Aslibekyan S, Absher DM, Hopkins PN, Sha J, Tsai MY, et al. Methylation at CPTI A locus is associated with lipoprotein subfraction profiles. Journal of lipid research. 2014;55(7):1324-30. Epub 2014/04/09. doi: 10.1194/jlr.M048504. PubMed PMID: 2471 1635; PubMed Central PMCID: PMCPMC4076093.

80. Breeze CE, Paul DS, van Dongen J, Butcher LM, Ambrose JC, Barrett JE, et al. eFORGE: A Tool for Identifying Cell Type-Specific Signal in Epigenomic Data. Cell Rep. 2016;17(8):2137-50. Epub 2016/1 1/17. doi: 10.1016/j.celrep.2016.10.059. PubMed PMID: 27851974; PubMed Central PMCID: PMCPMC5120369.

81. Ziller MJ, Gu H, Muller F, Donaghey J, Tsai LT, Kohlbacher O, et al. Charting a dynamic DNA methylation landscape of the human genome. Nature.

2013;500(7463):477-81. Epub 2013/08/09. doi: 10.1038/nature12433. PubMed PMID: 23925113 ; PubMed Central PMCID: PMCPmc3821869.

82. Aslibekyan S, Demerath EW, Mendelson M, Zhi D, Guan W, Liang L, et al. Epigenome-wide study identifies novel methylation loci associated with body mass index and waist circumference. Obesity (Silver Spring). 2015;23(7):1493-501. doi: 10.1002/oby.21111. PubMed PMID: 261 10892; PubMed Central PMCID: PMCPMC4482015.

83. Das M, Sha J, Hidalgo B, Aslibekyan S, Do AN, Zhi D, et al. Association of DNA Methylation at CPTIA Locus with Metabolic Syndrome in the Genetics of Lipid Lowering Drugs and Diet Network (GOLDN) Study. PLOS ONE. 2016;11 (1):e0145789. doi: 10.1371 /journal.pone.0145789.

84. Al Muftah WA, Al-Shafai M, Zaghlool SB, Visconti A, Tsai P-C, Kumar P, et al. Epigenetic associations of type 2 diabetes and $B M I$ in an Arab population. Clinical epigenetics. 2016;8(1):13. doi: 10.1186/s13148-016-0177-6.

85. Shah S, Bonder MJ, Marioni RE, Zhu Z, MCRae AF, Zhernakova A, et al. Improving Phenotypic Prediction by Combining Genetic and Epigenetic Associations. Am J Hum Genet. 2015;97(1):75-85. doi: 10.1016/j.ajhg.2015.05.014. PubMed PMID: 26119815 ; PubMed Central PMCID: PMCPMC4572498.

86. Gagnon F, Aissi D, Carrie A, Morange PE, Tregouet DA. Robust validation of methylation levels association at CPT1 A locus with lipid plasma levels. Journal of lipid research. 2014;55(7):1 189-91. Epub 2014/05/23. doi: 10.1194/jlr.E051276. PubMed PMID: 24850808; PubMed Central PMCID: PMCPMC4076097.

87. Irvin MR, Zhi D, Joehanes R, Mendelson M, Aslibekyan S, Claas SA, et al. <span hwp:id="article-title-1" class="article-title">Epigenome-Wide Association Study of Fasting Blood Lipids in the Genetics of Lipid-Lowering Drugs and Diet Network Study</span><span hwp:id="article-title-48" class="sub-article-title">CLINICAL PERSPECTIVE</span>. Circulation. 2014;130(7):565-72. doi:

10.1161/circulationaha.114.009158.

88. Pfeiffer L, Wahl S, Pilling LC, Reischl E, Sandling JK, Kunze S, et al. <span hwp:id="article-title-1" class="article-title">DNA Methylation of Lipid-Related Genes Affects Blood Lipid Levels</span><span hwp:id="article-title-46" class="sub-article- 
title">CLINICAL PERSPECTIVE</span>. Circulation: Cardiovascular Genetics. 2015;8(2):334-42. doi: 10.1161/circgenetics.114.000804.

89. Braun KVE, Dhana K, de Vries PS, Voortman T, van Meurs JBJ, Uitterlinden AG, et al. Epigenome-wide association study (EWAS) on lipids: the Rotterdam Study. Clinical epigenetics. 2017;9(1):15. doi: 10.1186/s13148-016-0304-4.

90. Kriebel J, Herder C, Rathmann W, Wahl S, Kunze S, Molnos S, et al. Association between DNA Methylation in Whole Blood and Measures of Glucose Metabolism: KORA F4 Study. PLoS One. 2016;1 1 (3):e0152314. Epub 2016/03/29. doi: 10.1371/journal.pone.0152314. PubMed PMID: 27019061; PubMed Central PMCID: PMCPMC4809492.

91. Mamtani M, Kulkarni H, Dyer TD, Göring HHH, Neary JL, Cole SA, et al. Genome- and epigenome-wide association study of hypertriglyceridemic waist in Mexican American families. Clinical epigenetics. 2016;8(1):6. doi: 10.1 186/s13148-0160173-x.

92. Ventham NT, Kennedy NA, Adams AT, Kalla R, Heath S, O'Leary KR, et al. Integrative epigenome-wide analysis demonstrates that DNA methylation may mediate genetic risk in inflammatory bowel disease. Nat Commun. 2016;7:13507. doi: $10.1038 /$ ncomms 13507

http://www.nature.com/articles/ncomms 13507 - supplementary-information.

93. Agouridis AP, Elisaf M, Milionis HJ. An overview of lipid abnormalities in patients with inflammatory bowel disease. Annals of Gastroenterology : Quarterly Publication of the Hellenic Society of Gastroenterology. 2011;24(3):181-7. PubMed PMID:

PMC3959314.

94. Benton MC, Johnstone A, Eccles D, Harmon B, Hayes MT, Lea RA, et al. An analysis of DNA methylation in human adipose tissue reveals differential modification of obesity genes before and after gastric bypass and weight loss. Genome Biol.

2015;16:8. Epub 2015/02/05. doi: 10.1186/s13059-014-0569-x. PubMed PMID: 25651499; PubMed Central PMCID: PMCPmc4301800.

95. Horvath S, Erhart W, Brosch M, Ammerpohl O, von Schonfels W, Ahrens M, et al. Obesity accelerates epigenetic aging of human liver. Proc Natl Acad Sci U S A. 2014;1 11 (43):15538-43. doi: 10.1073/pnas.1412759111. PubMed PMID: 25313081; PubMed Central PMCID: PMCPMC4217403.

96. Simpkin AJ, Howe LD, Tilling K, Gaunt TR, Lyttleton O, McArdle WL, et al. The epigenetic clock and physical development during childhood and adolescence: longitudinal analysis from a UK birth cohort. Int J Epidemiol. 2017. Epub 2017/01/17. doi: 10.1093/ije/dyw307. PubMed PMID: 28089957.

97. Nevalainen T, Kananen L, Marttila S, Jylhävä J, Mononen N, Kähönen M, et al. Obesity accelerates epigenetic aging in middle-aged but not in elderly individuals. Clinical epigenetics. 2017;9:20. doi: 10.1 186/s13148-016-0301-7. PubMed PMID: PMC5310016.

98. Faulk C, Dolinoy DC. Timing is everything: The when and how of environmentally induced changes in the epigenome of animals. Epigenetics. 2011;6(7). Epub 2011/06/04. PubMed PMID: 21636976.

99. Dominguez-Salas P, Moore SE, Baker MS, Bergen AW, Cox SE, Dyer RA, et al. Maternal nutrition at conception modulates DNA methylation of human metastable epialleles. Nat Commun. 2014;5. doi: 10.1038/ncomms4746.

100. Gluckman PD, Hanson MA, Cooper C, Thornburg KL. Effect of in utero and early-life conditions on adult health and disease. N Engl J Med. 2008;359(1):61-73. Epub 2008/07/04. doi: 359/1/61 [pii] 10.1056/NEJMra0708473. PubMed PMID: 18596274.

101. Guénard F, Deshaies Y, Cianflone K, Kral JG, Marceau P, Vohl M-C. Differential methylation in glucoregulatory genes of offspring born before vs. after maternal gastrointestinal bypass surgery. Proceedings of the National Academy of Sciences. 2013;110(28):11439-44. doi: 10.1073/pnas.1216959110.

102. Sharp GC, Lawlor DA, Richmond RC, Fraser A, Simpkin A, Suderman M, et al. Maternal pre-pregnancy BMI and gestational weight gain, offspring DNA methylation 
and later offspring adiposity: findings from the Avon Longitudinal Study of Parents and Children. Int J Epidemiol. 2015:dyv042.

103. Sorensen T, Ajslev TA, Angquist L, Morgen CS, Ciuchi IG, Davey Smith G. Comparison of associations of maternal peri-pregnancy and paternal

anthropometrics with child anthropometrics from birth through age $7 \mathrm{y}$ assessed in the Danish National Birth Cohort. Am J Clin Nutr. 2016;104(2):389-96. doi:

10.3945/ajcn.115.129171. PubMed PMID: 27413126.

104. Horikoshi M, Beaumont RN, Day FR, Warrington NM, Kooijman MN, FernandezTajes J, et al. Genome-wide associations for birth weight and correlations with adult disease. Nature. 2016;538(7624):248-52. Epub 2016/09/30. doi: 10.1038/nature19806. PubMed PMID: 27680694; PubMed Central PMCID: PMCPMC5164934.

105. Richmond RC, Timpson NJ, Felix JF, Palmer T, Gaillard R, MCMahon G, et al. Using Genetic Variation to Explore the Causal Effect of Maternal Pregnancy Adiposity on Future Offspring Adiposity: A Mendelian Randomisation Study. PLOS Med. 2017;14(1):e1002221. Epub 2017/01/25. doi: 10.1371/journal.pmed.1002221. PubMed PMID: 28118352.

106. Lawlor D, Richmond R, Warrington N, McMahon G, Davey Smith G, Bowden J, et al. Using Mendelian randomization to determine causal effects of maternal pregnancy (intrauterine) exposures on offspring outcomes: Sources of bias and methods for assessing them [version 1; referees: awaiting peer review] 2017.

107. Leung D, Jung I, Rajagopal N, Schmitt A, Selvaraj S, Lee AY, et al. Integrative analysis of haplotype-resolved epigenomes across human tissues. Nature. 2015;518(7539):350-4. doi: 10.1038/nature14217. PubMed PMID: 25693566.

108. Kuehnen P, Mischke M, Wiegand S, Sers C, Horsthemke B, Lau S, et al. An Alu element-associated hypermethylation variant of the POMC gene is associated with childhood obesity. PLoS Genet. 2012;8(3):e1002543. Epub 2012/03/23. doi: 10.1371/journal.pgen.1002543. PubMed PMID: 22438814; PubMed Central PMCID: PMCPMC3305357.

109. Jaffe AE, Murakami P, Lee H, Leek JT, Fallin MD, Feinberg AP, et al. Bump hunting to identify differentially methylated regions in epigenetic epidemiology studies. Int J Epidemiol. 2012;41 (1):200-9. Epub 2012/03/17. doi: 10.1093/ije/dyr238. PubMed PMID: 22422453; PubMed Central PMCID: PMC3304533.

110. Liu Y, Aryee MJ, Padyukov L, Fallin MD, Hesselberg E, Runarsson A, et al. Epigenome-wide association data implicate DNA methylation as an intermediary of genetic risk in rheumatoid arthritis. Nat Biotech. 2013;31 (2):1 142-7. doi: 10.1038/nbt.2487 http://www.nature.com/nbt/journal/v31/n2/abs/nbt.2487.html - supplementaryinformation.

111. Lillycrop KA, Burdge GC. Epigenetic mechanisms linking early nutrition to long term health. Best Practice \& Research Clinical Endocrinology \& Metabolism. 2012;26(5):667-76. doi: 10.1016/j.beem.2012.03.009.

112. Petersen AK, Zeilinger S, Kastenmuller G, Romisch-Margl W, Brugger M, Peters $A$, et al. Epigenetics meets metabolomics: an epigenome-wide association study with blood serum metabolic traits. Hum Mol Genet. 2014;23(2):534-45. Epub 2013/09/10. doi: 10.1093/hmg/ddt430. PubMed PMID: 24014485; PubMed Central PMCID: PMCPmc3869358.

113. Ecker S, Chen L, Pancaldi V, Bagger FO, Fernández JM, Carrillo de Santa Pau E, et al. Genome-wide analysis of differential transcriptional and epigenetic variability across human immune cell types. Genome Biology. 2017;18(1):18. doi:

10.1186/s13059-017-1156-8.

114. Ward LD, Kellis M. HaploReg v4: systematic mining of putative causal variants, cell types, regulators and target genes for human complex traits and disease. Nucleic Acids Res. 2016;44(D1):D877-81. Epub 2015/12/15. doi: 10.1093/nar/gkv1340. PubMed PMID: 26657631; PubMed Central PMCID: PMCPMC4702929.

115. Claussnitzer M, Dankel SN, Kim K-H, Quon G, Meuleman W, Haugen C, et al. FTO Obesity Variant Circuitry and Adipocyte Browning in Humans. New England 
Journal of Medicine. 2015;373(10):895-907. doi: doi:10.1056/NEJMoa1502214. PubMed PMID: 26287746.

116. Jufvas A, Sjodin S, Lundqvist K, Amin R, Vener AV, Stralfors P. Global differences in specific histone $\mathrm{H} 3$ methylation are associated with overweight and type 2 diabetes. Clinical epigenetics. 2013;5(1):15. Epub 2013/09/06. doi: 10.1 186/1868-7083-5-15. PubMed PMID: 24004477; PubMed Central PMCID: PMCPMC3766271.

117. Pazienza V, Panebianco C, Rappa F, Memoli D, Borghesan M, Cannito S, et al. Histone macroH2A1.2 promotes metabolic health and leanness by inhibiting adipogenesis. Epigenetics \& chromatin. 2016;9:45. doi: 10.1186/s13072-016-0098-9. PubMed PMID: 27800025; PubMed Central PMCID: PMCPMC5078890.

118. Sun W, Poschmann J, Cruz-Herrera Del Rosario R, Parikshak NN, Hajan HS, Kumar $\mathrm{V}$, et al. Histone Acetylome-wide Association Study of Autism Spectrum Disorder. Cell. 2016;167(5):1385-97 e1 1. doi: 10.1016/j.cell.2016.10.031. PubMed PMID: 27863250.

119. Bell CG. The emerging potential for epigenetic therapeutics in noncancer disorders. 2016.

120. Razak F, Davey Smith G, Subramanian SV. The idea of uniform change: is it time to revisit a central tenet of Rose's "Strategy of Preventive Medicine"? Am J Clin Nutr. 2016;104(6):1497-507. Epub 2016/12/10. doi: 10.3945/ajcn.115.127357. PubMed PMID: 27935518.

121. Bolton JL, Smith SH, Huff NC, Gilmour MI, Foster WM, Auten RL, et al. Prenatal air pollution exposure induces neuroinflammation and predisposes offspring to weight gain in adulthood in a sex-specific manner. Faseb J. 2012;26(11):4743-54. Epub 2012/07/21. doi: 10.1096/fj.12-210989. PubMed PMID: 22815382.

122. Park S, Skaar D, Jirtle RL, Hoyo C. Epigenetics, obesity and early-life cadmium or lead exposure. Epigenomics. 2016:9(1):57-75. doi: 10.2217/epi-2016-0047.

123. Burgio E, Lopomo A, Migliore L. Obesity and diabetes: from genetics to epigenetics. Molecular biology reports. 2015;42(4):799-818. Epub 2014/09/26. doi: 10.1007/s1 1033-014-3751-z. PubMed PMID: 25253098.

124. Bojesen SE, Timpson N, Relton C, Davey Smith G, Nordestgaard BG. AHRR (cg05575921) hypomethylation marks smoking behaviour, morbidity and mortality. Thorax. 2017. Epub 2017/01/20. doi: 10.1136/thoraxjnl-2016-208789. PubMed PMID: 28100713.

125. Hedman ÅK, Mendelson MM, Marioni RE, Gustafsson S, Joehanes R, Irvin MR, et al. Epigenetic Patterns in Blood Associated with Lipid Traits Predict Incident Coronary Heart Disease Events and Are Enriched for Results from Genome-Wide Association Studies. Circ Cardiovasc Genet. 2017;10(1):e001487. doi: 10.1161/CIRCGENETICS.116.001487. PubMed PMID: PMC5331877.

126. Simpson JT, Workman RE, Zuzarte PC, David M, Dursi LJ, Timp W. Detecting DNA cytosine methylation using nanopore sequencing. Nat Meth. 2017; advance online publication. doi: 10.1038/nmeth.4184 http://www.nature.com/nmeth/journal/vaop/ncurrent/abs/nmeth.4184.html supplementary-information. 

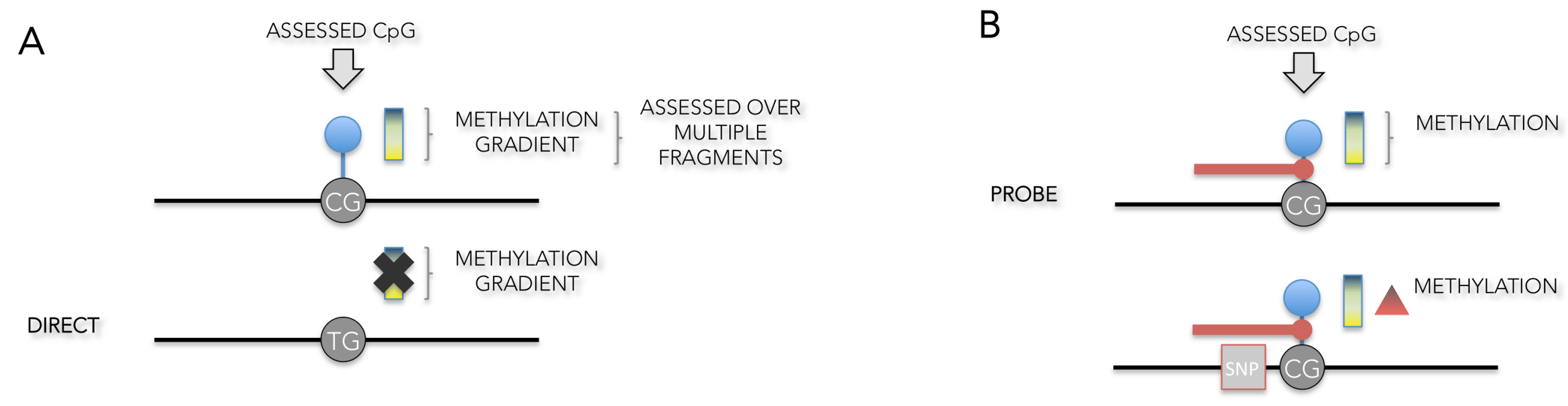

C

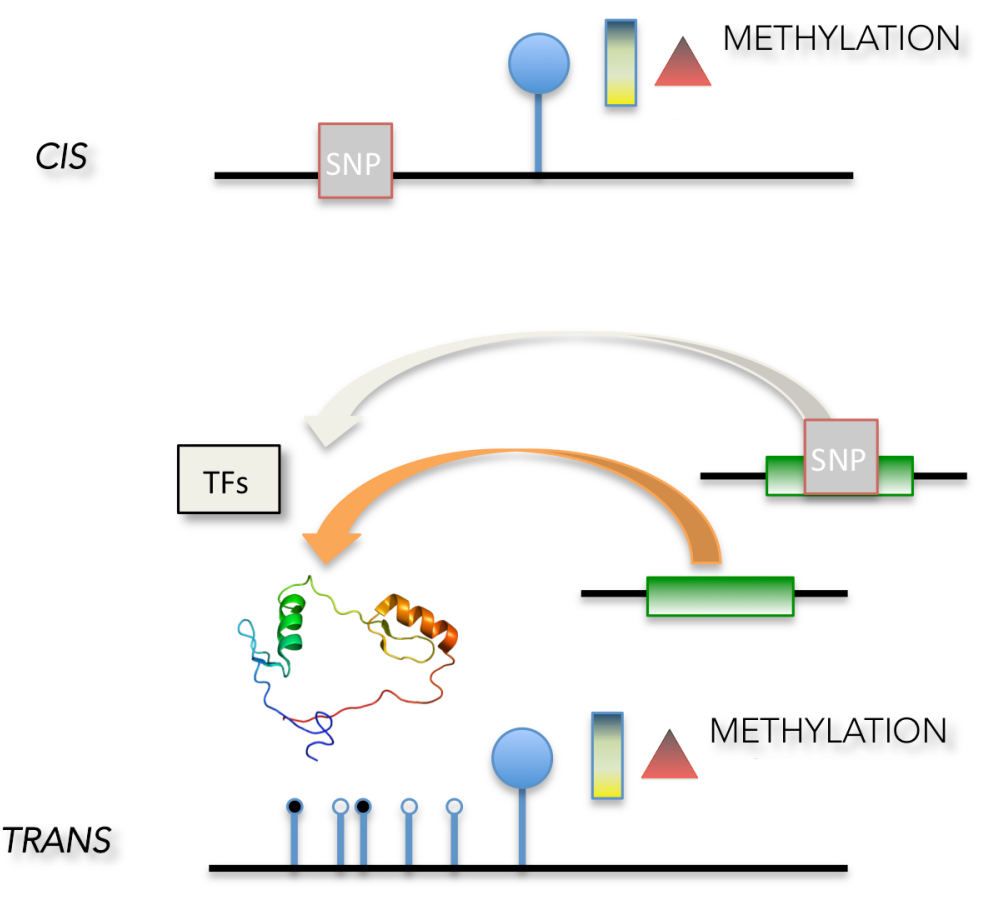

D

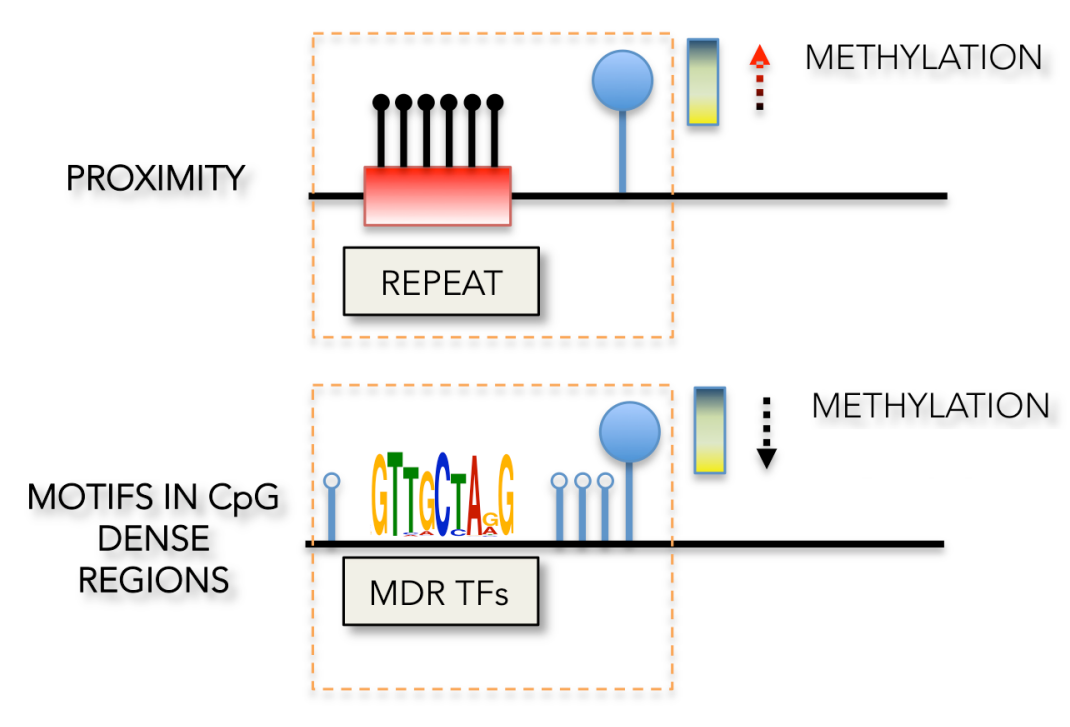

E

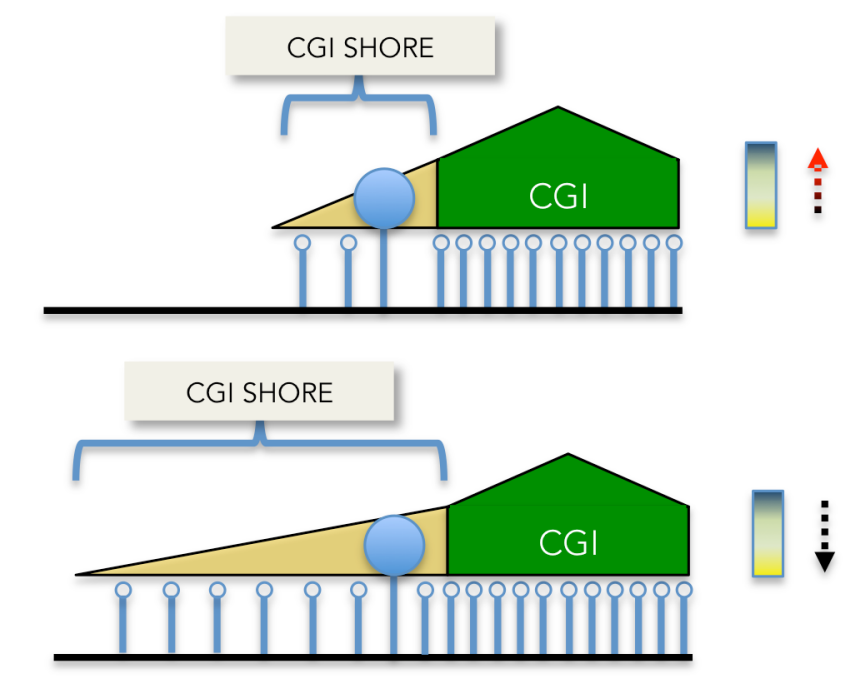


\# GREAT version 3.0.0 Species assembly: hg19 Association rule: Basaltextension: 5000 bp upstream, 1000 bp downstream, 1000000 bp max extension, curated regulatory domains included
\# Ontology
Term Name
Hyper Rank
Hyper Raw P-Value Hyper Bonferroni P-Value Hyper FDR Q-Val Hyper Fold Enrichment Hyper Expected Hyper Foreground Region Hits Hyper Total Regions Hyper Region Set Coverage Hyper Term Region Coverage Hyper Foreground Gene Hits Hyper Background Gene Hits Total Genes Annotated GO Molecular Function sterol-transporting ATPase activity 1 $\begin{array}{ccccccc}0.001255707 & 1 & 1 & 795.9213 & 0.001256406 & 1 \\ 61 & 0.1 & 0.01639344 & 1 & 1 & 1 & 1\end{array}$ GO Molecular Function glycoprotein transporter activity 2 $\begin{array}{llllll}0.001975554 & 1 & 1 & 505.7417 & 0.001977294 & 1\end{array}$ $\begin{array}{llllll}96 & 0.1 & 0.01041667 & 1 & 2 & 2\end{array}$

GO Molecular Function sterol response element binding 3

$\begin{array}{llllll}0.003557574 & 1 & 1 & 280.6428 & 0.003563249 & 1\end{array}$

$\begin{array}{llllll}173 & 0.1 & 0.005780347 & 1 & 2 & 2\end{array}$

GO Molecular Function carnitine O-palmitoyltransferase activity

$\begin{array}{llllll}0.003886021 & 1 & 1 & 256.8847 & 0.003892798 & 1\end{array}$

$\begin{array}{llllll}189 & 0.1 & 0.005291005 & 1 & 4\end{array}$

GO Molecular Function dynein intermediate chain binding 5

$\begin{array}{lllllll}0.004214372 & 1 & 1 & 236.8351 & 0.004222347 & 1\end{array}$

$\begin{array}{llllll}205 & 0.1 & 0.004878049 & 1 & 2 & 2\end{array}$

GO Molecular Function carnitine O-acyltransferase activity 6

$\begin{array}{ccccccc}0.004706715 & 1 & 1 & 212.014 & 0.00471667 & 1 \\ 229 & 0.1 & 0.004366812 & 1 & 6 & 6 & \end{array}$

GO Biological Process positive regulation of cholesterol biosynthetic $\begin{array}{lllll}\text { process } 1 & 0.0000320249 & 0.334339956 & 0.334339956\end{array}$

$\begin{array}{llllll}236.2589 & 0.00846529 & 2 & 411 & 0.2 & 0.00486618\end{array}$

5 GO Biological Process positive regulation of cholesterol metabolic

$\begin{array}{llll}\text { process } 2 & 0.0000385532 & 0.402495408 & 0.201247704\end{array}$

$\begin{array}{llllll}215.3047 & 0.009289163 & 2 & 451 & 0.2 & 0.00443459\end{array}$

66 6 6.009289163645

GO Biological Process regulation of cholesterol biosynthetic process 3

$\begin{array}{cccccc}0.0001002341 & 1 & 0.348814668 & 133.3824 & 0.01499448 & 2\end{array}$

$\begin{array}{llllll}728 & 0.2 & 0.002747253 & 2 & 12 & 12\end{array}$

GO Biological Process intracellular lipid transport 4

$\begin{array}{llrrr}0.0001227746 & 1 & 0.320441706 & 120.4744 & 0.01660103\end{array}$

$\begin{array}{llllll}806 & 0.2 & 0.00248139 & 2 & 19 & 19\end{array}$

Go Biological Process positive regulation of lipid metabolic process 5

$\begin{array}{llllll}0.0001617343 & 1 & 0.3377012184 & 26.62285 & 0.11268523\end{array}$

$\begin{array}{llllll}5471 & 0.3 & 0.0005483458 & 3 & 99 & 99\end{array}$

GO Biological Process positive regulation of steroid biosynthetic

$\begin{array}{cccccc}\text { process } 6 & 0.0003000956 & 1 & 0.5221663440000001 & 76.88234 \\ 0.02601378 & 2 & 1263 & 0.2 & 0.001583531 & 2\end{array}$

12.02601378

GO Biological Process

$\begin{array}{cccccc}0.0003043593 & 1 & 0.4539301560000001 & 76.33836 & 0.02619915 \\ 1272 & 0.2 & 0.001572327 & 2 & 19 & 19\end{array}$

regulation of cholesterol metabolic process 7

Go Biological process organic hydroxy compound metabolic process

$0.0004124473 \quad 1 \quad 0.538243726500000110 .18646 \quad 0.39267824$

$\begin{array}{llllll}19065 & 0.4 & 0.0002098085 & 4 & 408 & 408\end{array}$

GO Biological process positive regulation of steroid metabolic process

$90.0004172274 \quad 0 \quad 1 \quad 0.4839837840000000365 .125690 .03070985$

$\begin{array}{lllllll}2 & 1491 & 0.2 & 0.001341382 & 2 & 21 & 21\end{array}$

GO Biological Process negative regulation of secretion 10

$\begin{array}{lllll}0.000502318 & 1 & 0.524419992 & 18.07789 & 0.16594853\end{array}$

$\begin{array}{llllll}8057 & 0.3 & 0.000372347 & 3 & 134 & 134\end{array}$

GO Biological Process negative regulation of insulin secretion 


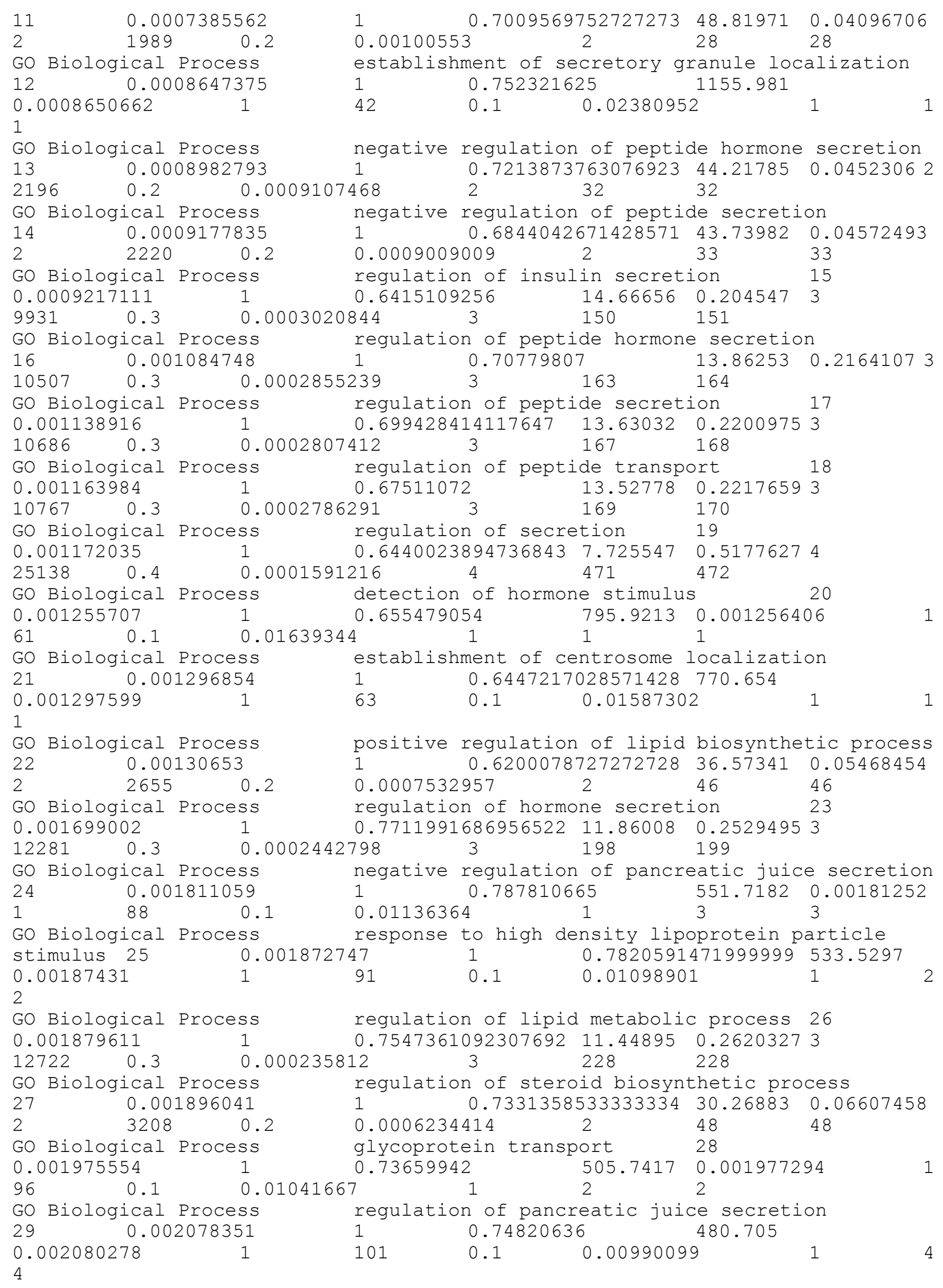




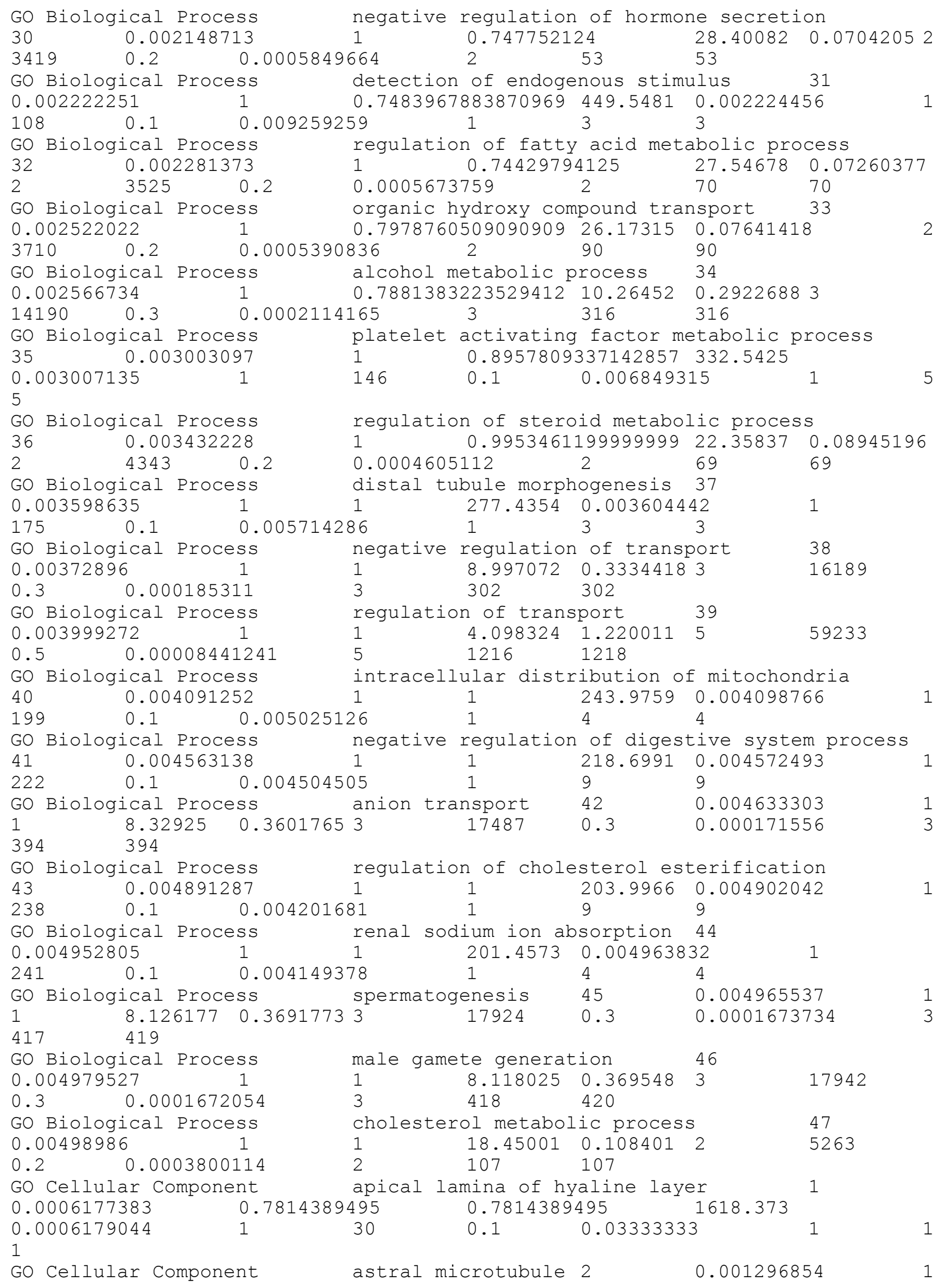




\begin{tabular}{|c|c|c|c|c|c|}
\hline 0.820260155 & 0.0012975 & & 1 & 63 & 0.1 \\
\hline & $\begin{array}{lc}1 & 1\end{array}$ & 1 & & & \\
\hline $\begin{array}{l}\text { Mouse Phenotype } \\
0.001296854\end{array}$ & $\begin{array}{l}\text { absent hippocampus } \\
1\end{array}$ & stratum or & riens & $\begin{array}{c}1 \\
99\end{array}$ & 1 \\
\hline $63 \quad 0.1$ & $0.01587302^{\perp}$ & 1 & 1 & 1 & \\
\hline Mouse Phenotype & abnormal hippocampu & s stratum & oriens mor & rphology & 2 \\
\hline 0.001769931 & 111 & 564.5488 & 0.00177132 & & 1 \\
\hline 0.1 & 0.01162791 & 1 & 2 & 2 & \\
\hline Mouse Phenotype & decreased pro-B cel & 1 number & 3 & 0.00199957 & \\
\hline $\begin{array}{lll}1 & 29.46068 & 0 \\
58 & 58 & \end{array}$ & 0.06788712 & 3296 & 0.2 & 0.00060679 & 961 \\
\hline Mouse Phenotype & increased interleuk & in-23 secr & retion & 4 & \\
\hline 0.003372779 & 1 & 296.0439 & 0.00337787 & & 1 \\
\hline 0.1 & 0.006097561 & 1 & 5 & 5 & \\
\hline Mouse Phenotype & decreased pre-B cel & 1 number & 5 & 0.00429777 & \\
\hline $\begin{array}{lll}1 & 19.92253 & 0 \\
90 & 90\end{array}$ & 0.10038892 & 4874 & 0.2 & 0.0004 & 406 \\
\hline Mouse Phenotype & increased early pro & -B cell nu & lumber & 6 & \\
\hline 0.004481085 & 1 & 222.7119 & 0.00449010 & & 1 \\
\hline 0.1 & 0.004587156 & 1 & 4 & 4 & \\
\hline Mouse Phenotype & abnormal lipid leve & & 7 & 0.00467830 & \\
\hline $\begin{array}{lll}1 & 5.307012 & 0 \\
765 & 767\end{array}$ & 0.75371984 & 36594 & 0.4 & 0.0 & 075 \\
\hline Mouse Phenotype & decreased circulati & ng magnesi & ium level $\varepsilon$ & 8 & \\
\hline 0.004727225 & 1 & 211.0922 & 0.00473726 & & 1 \\
\hline 0.1 & 0.004347826 & 1 & 7 & 7 & \\
\hline Mouse Phenotype & abnormal pro-B cell & morpholog & & 9 & \\
\hline 0.004901835 & 1 & 18.61983 & 0.10741242 & 2 & 5215 \\
\hline 0.00 & 091 & 99 & 99 & & \\
\hline Mouse Phenotype & alkalosis 10 & 0.0049117 & & & 1 \\
\hline $\begin{array}{ll}203.1431 & 0.004922638 \\
5 & \end{array}$ & 38 & 239 & 0.1 & 0.0041841 & 1 \\
\hline Human Phenotype & Hyperlipidemia & 1 & 0.00035783 & 343 & 1 \\
\hline $\begin{array}{ll}70.36406 & 0.02842362 \\
40 & 40\end{array}$ & 1380 & 0.2 & 4927 & & 2 \\
\hline Human Phenotype & Recurrent encephalo & pathy & 2 & 0.00 & \\
\hline $\begin{array}{ll}551.7182 & 0 \\
1 & 1\end{array}$ & 0.00181252 & 1 & 88 & 0 . & 0.01 \\
\hline Human Phenotype & Transient hyperlipi & demia & 2 & 0. & \\
\hline $551.7182 \quad 0$ & 81252 & 1 & 88 & 0 . & 0 . \\
\hline 1 & 1 & & & & \\
\hline Human Phenotype & Pseudohypoaldostero & nism & 4 & 28391 & \\
\hline $437.3982 \quad 0$ & 286246 & 1 & 111 & 0 . & \\
\hline 0.009009009 & 4 & 4 & & & \\
\hline Human Phenotype & Abnormality of lipi & d metaboli & ism & 5 & \\
\hline 0.002582305 & 1 & 25.85949 & 0.07734103 & & 2 \\
\hline 3755 & 26232 & 2 & 107 & 107 & \\
\hline Human Phenotype & Head-banging & 6 & 0.00267438 & & 1 \\
\hline $\begin{array}{ll}373.4708 & 0.00267758 \\
1 & 1\end{array}$ & 86 & 130 & 0.1 & 9230 & \\
\hline Human Phenotype & Hyperchloremia & 7 & 0.00300309 & & 1 \\
\hline $\begin{array}{ll}332.5425 & 0.003007135 \\
4 & 4\end{array}$ & $35^{4}$ & 146 & 0.1 & 4931 & \\
\hline Human Phenotype & Sporadic 8 & 0.003 & & & 1 \\
\hline $\begin{array}{ll}23.84637 & 0.08387022 \\
52 & 52\end{array}$ & 2 & 4072 & 0.2 & 0.00049115 & 591 \\
\hline Human Phenotype & Hyperacusis & 9 & 0.00444005 & & 1 \\
\hline $\begin{array}{ll}224.7741 & 0.004448912 \\
2 & 2\end{array}$ & 12 & 216 & 0.1 & 0.00462963 & \\
\hline Human Phenotype & Hypoket & & 10 & 0.00499381 & \\
\hline
\end{tabular}




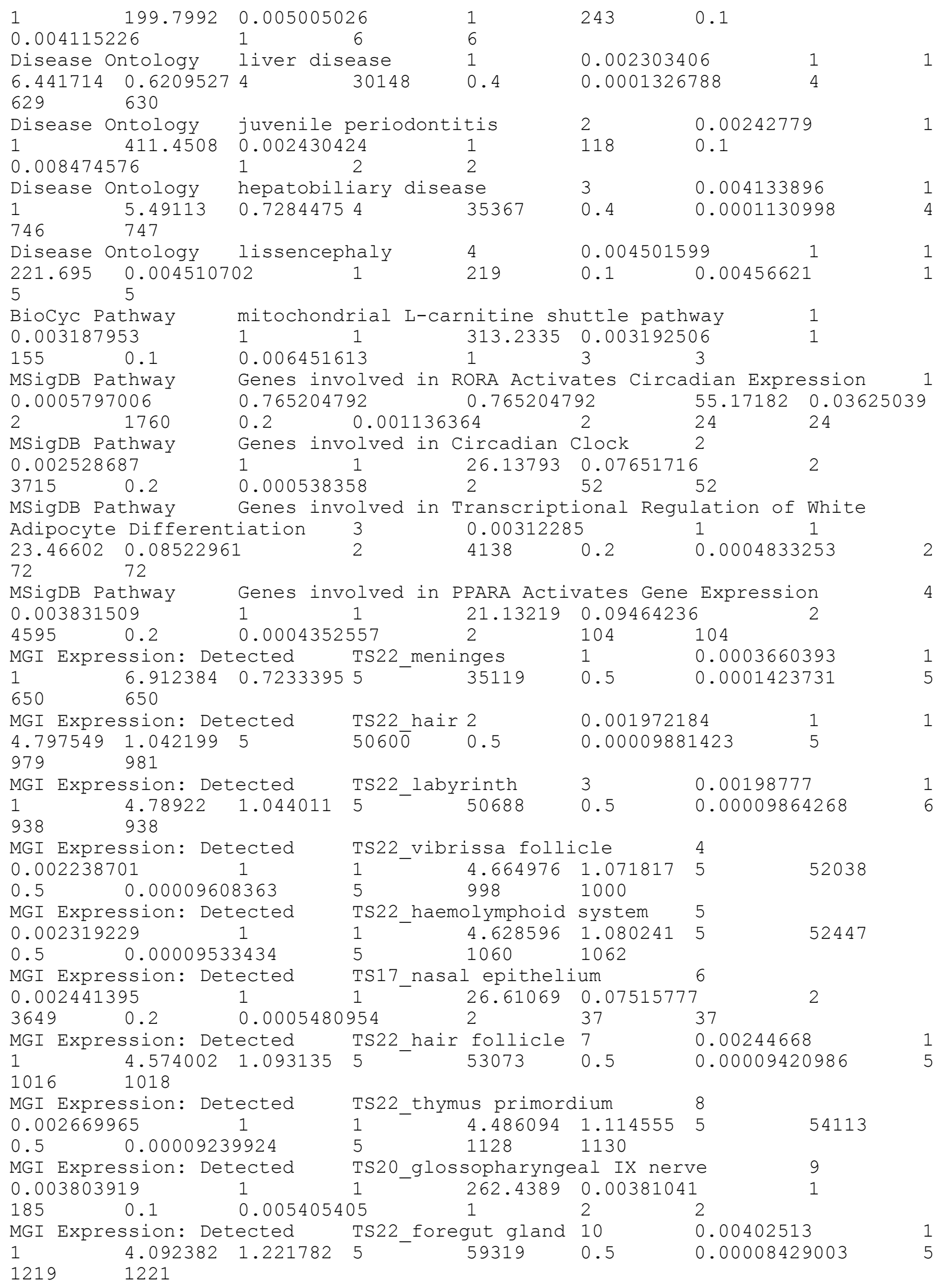


MGI Expression: Detected

$\begin{array}{lll}1 & 4.057972 & 1.232143 \\ 1129 & 1131\end{array}$

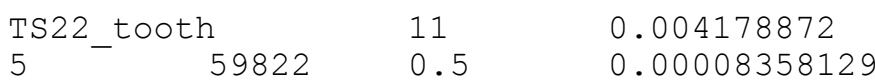

1

MGI Expression: Detected

$\begin{array}{ccc}0.004183018 & 1 \\ 0.7 & 0.00005603855\end{array}$

MGI Expression: Detected

$4.053906 \quad 1.233378 \quad 5$

$1131 \quad 1133$

TS28_female reproductive system 12

$1-2.7207392 .57283^{7} \quad 2.124914$

$8 \quad 2538 \quad 2574$

TS22 jaw $13 \quad 0.004197498$

$5988 \overline{2} \quad 0.5 \quad 0.00008349755$

$$
1
$$

5

MSigDB PerturbationGenes down-regulated between two breast carcinoma subtypes: metaplastic (MCB) and ductal (DCB). $1 \quad 0.00007821423$

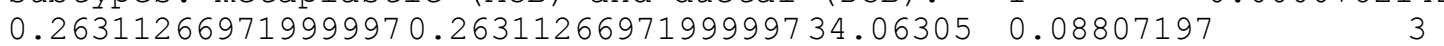
$\begin{array}{llllll}4276 & 0.3 & 0.0007015903 & 3 & 106 & 106\end{array}$

MSigDB PerturbationGenes which best discriminated between two groups of breast cancer according to the status of ESR1 and AR [GeneID=2099;367]: basal $(\mathrm{ESR} 1-\mathrm{AR}-)$ and luminal (ESR1+ AR+). $2 \quad 0.0002138256$

$\begin{array}{ccclll}0.7193093184 & 0.3596546592 & 12.09622 & 0.33068184 & 16055 \\ 0.4 & 0.0002491436 & 4 & 322 & 322 & \end{array}$

MSigDB PerturbationGenes up-regulated in bulk samples from early primary breast tumors expressing ESR1 [GeneID=2099] vs the ESR1 negative samples. $\begin{array}{lllllll}0.0003067409 & 1 & 0.3439587958666666 & 76.03947 & 0.02630213\end{array}$
1277
0.2
0.001566171
2
26
26

MSigDB PerturbationGenes up-regulated in the luminal B subtype of breast $\begin{array}{llllll}\text { cancer. } 4 & 0.0004514236 & 1 & 0.3796472476 & 18.75288\end{array}$

$\begin{array}{llllll}0.15997543 & 7767 & 0.3 & 0.0003862495 & 3 & 160\end{array}$

160

MSigDB PerturbationUp-regulated genes from the optimal set of 550 markers discriminating breast cancer samples by ESR1 [GeneID=2099] expression: ER(+)

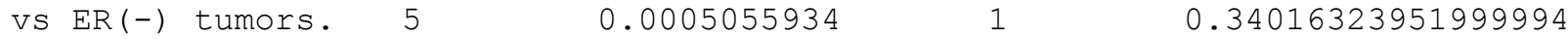
$\begin{array}{llllll}18.0376 & 0.16631933 & 8075 & 0.3 & 0.000371517 & 3\end{array}$ $156 \quad 156$ MSigDB PerturbationGenes up-regulated in the liver tissue from 10 week old male mice with KLF10 [GeneID=7071]. $6 \quad 6 \quad 0.0006357855 \quad 1$ $0.3564637369999999552 .65857 \quad 0.03798052$ $0.001084599 \quad 2 \quad 50 \quad 50$ MSigDB PerturbationGenes important for spermatid differentiation, based on mouse models with male reproductive defects. $7 \quad 0.0007224791$ $0.3472028132 \quad 49.36573 \quad 0.04051393$ $0.001016777 \quad 2 \quad 37 \quad 37$ MSigDB PerturbationGenes up-regulated in group C of tumors arising from overexpression of BCL2L1 and MYC [GeneID=598;4609] in plasma cells. 8
0.00132112
$1 \quad 0.55553096$
36.36794
0.05499349

2670

0.0007490637

MSigDB PerturbationGenes up-regulated in hepatocellular carcinoma (HCC)

induced by ciprofibrate [PubChem=2763]. $\quad 9.00136041$

$\begin{array}{lllllll}0.5084910266666667 & 35.83114 & 0.05581736 & 2 & 2710 & 0.2\end{array}$

$0.0007380074 \quad 2 \quad 59 \quad 59$

MSigDB PerturbationCluster 5: genes changed in primary keratinocytes by UVB

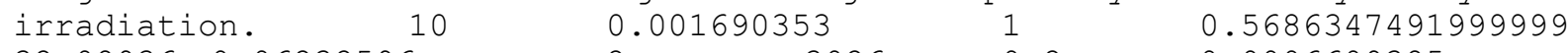
$\begin{array}{llllll}32.08936 & 0.06232596 & 2 & 3026 & 0.2 & 0.0006609385\end{array}$

$46 \quad 46$

MSigDB PerturbationGenes correlated with the early tumor onset in the Emu-myc transgenic mouse lymphoma model. 11 $\begin{array}{llll}22.01369 & 0.09085254 & 2 & 441 \\ 108 & 108 & \end{array}$ 10.003537915

MSigDB Perturbation Genes up-regulated in immature bone marrow progenitor cells upon knock out of CBFA2T3 [GeneID=863]. $12 \quad 0.004276857 \quad 1$ $\begin{array}{llllll}1 & 8.569875 & 0.35006343 & 16996 & 0.3 & 0.0001765121\end{array}$ $376 \quad 376$ MSigDB Predicted Promoter Motifs

Motif TGACGTYA matches JUN: jun 


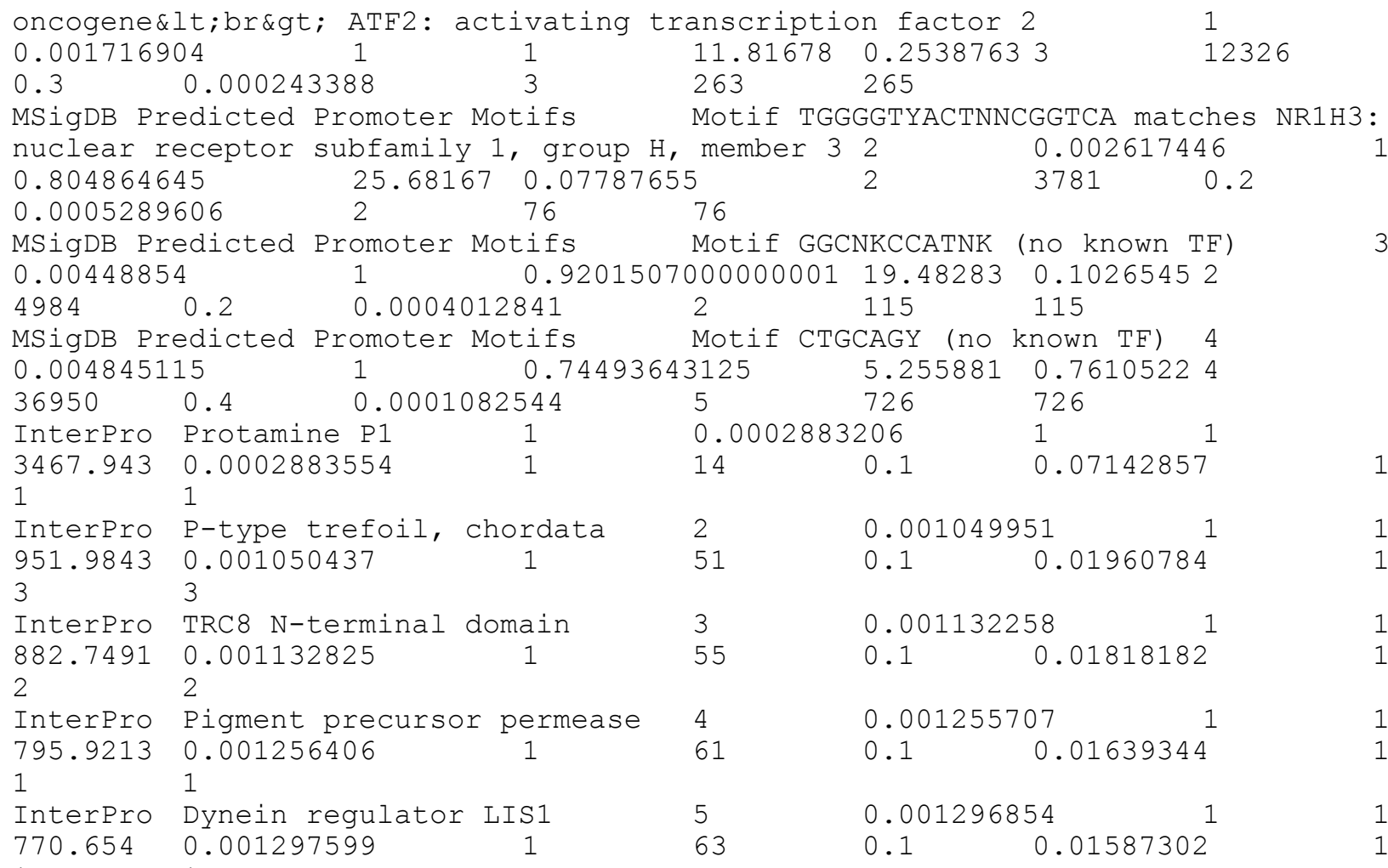

InterPro Lymphocyte antigen 6 complex

$\begin{array}{ccc}0.001502564 & 1 & 1 \\ 73 & 0.1 & 0.01369863^{1}\end{array}$

InterPro G-protein beta WD-40 repeat 7

$32.4215 \quad 0.06168746 \quad 299$

$81 \quad 81$

InterPro Clustered mitochondria protein

$1 \quad 511.0653 \quad 0.001956697 \quad 1$

0.1

0.01587302

locus protein G6d/G6f $\quad 6$

12

$2995 \quad 0.0016564550 .0006677796$

$\begin{array}{lllll}\text { InterPro CLU domain } & 8 & 0.001954993 & 1 & 1\end{array}$

$\begin{array}{lllllll}511.0653 & 0.001956697 & 1 & 95 & 0.1 & 0.01052632\end{array}$

1 InterPro $\quad$ Clustered mitochondria protein, N-terminal 8

$\begin{array}{lllll}0.001954993 & 1 & 1 & 511.0653 & 0.001956697\end{array}$

$95 \quad 0.1 \quad 0.01052632$

InterPro Protein LIN54/Tesmin

$500.5278 \quad 0.001997891 \quad 1$

2

InterPro CRC domain 11

$500.5278 \quad 0.001997891 \quad 1$

2

InterPro GSKIP domain 13

$394.7252 \quad 0.002533408$

22

InterPro Domain of unknown function DUF3456 1

$\begin{array}{lcc}1 & 334.8359 & 0.002986538\end{array}$

InterPro $\mathrm{ABC}-2$ type transporter 15

$332.54250 .003007135 \quad 1 \quad 14$

$\begin{array}{llc}1 & 1 & 1 \\ 11 & 0.001996114 & 1\end{array}$

$\begin{array}{lll}97 & 0.1 & 0.01030928\end{array}$

5

InterPro Guanine nucleotide-binding protein, beta subunit 16

0.003865496

1

258.25110 .003872201

$1 \quad 1$

.001996114

$97 \quad 0.1 \quad 0.01030928$

1

$.002530545 \quad 1 \quad 1$

$\begin{array}{lll}123 & 0.1 & 0.008130081\end{array}$

1

$145 \quad 0.1$

6

0.003003097

.002982555

1

$0.003003097 \quad 0.11$

$\begin{array}{llll}46 & 0.1 & 0.006849315 & 1\end{array}$ 


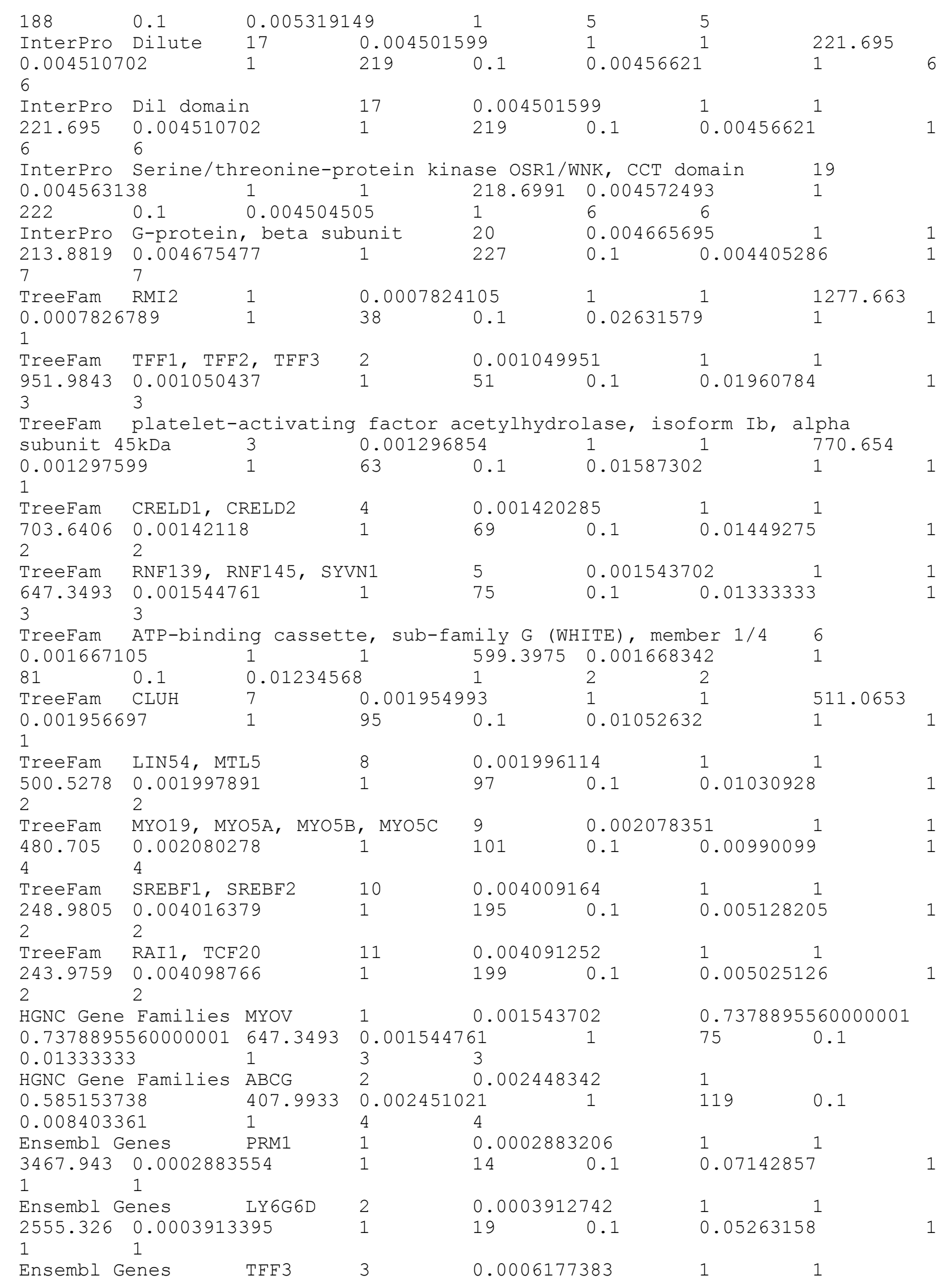




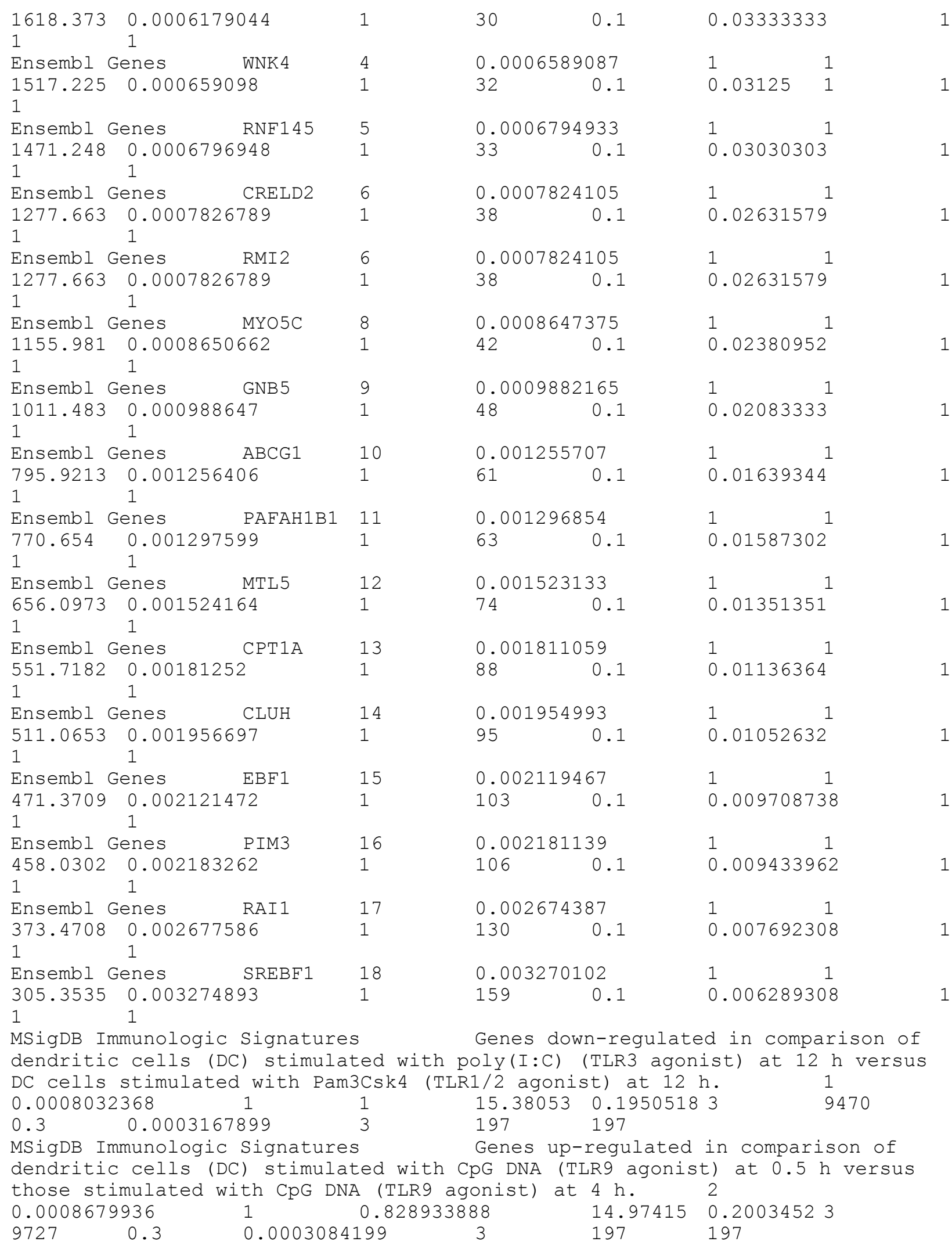

